\title{
aB-Crystallin Regulates Subretinal Fibrosis by Modulation of Epithelial-Mesenchymal Transition
}

\author{
Keijiro Ishikawa, ${ }^{* \dagger}$ Parameswaran G. Sreekumar, ${ }^{*}$ Christine Spee,${ }^{\dagger}$ Hossein Nazari, ${ }^{\dagger}$ Danhong Zhu,${ }^{\ddagger}$ Ram Kannan, ${ }^{*}$ and \\ David R. Hinton ${ }^{\dagger \ddagger}$
}

From the Arnold and Mabel Beckman Macular Research Center, * Doheny Eye Institute, Los Angeles; and the Departments of Ophthalmology ${ }^{\dagger}$ and Pathology, ${ }^{\ddagger}$ Keck School of Medicine of the University of Southern California, Los Angeles, California

\author{
Accepted for publication \\ November 19, 2015. \\ Address correspondence to \\ David R. Hinton, M.D., \\ Departments of Ophthalmology \\ and Pathology, Keck School of \\ Medicine of the University of \\ Southern California, 2011 \\ Zonal Ave, Hoffman Medical \\ Research 209, Los Angeles, CA \\ 90033. E-mail: dhinton@usc. \\ edu.
}

\begin{abstract}
Subretinal fibrosis is an end stage of neovascular age-related macular degeneration, characterized by fibrous membrane formation after choroidal neovascularization. An initial step of the pathogenesis is an epithelial-mesenchymal transition (EMT) of retinal pigment epithelium cells. $\alpha \mathrm{B}$-crystallin plays multiple roles in age-related macular degeneration, including cytoprotection and angiogenesis. However, the role of $\alpha \mathrm{B}$-crystallin in subretinal EMT and fibrosis is unknown. Herein, we showed attenuation of subretinal fibrosis after regression of laser-induced choroidal neovascularization and a decrease in mesenchymal retinal pigment epithelium cells in $\alpha \mathrm{B}$-crystallin knockout mice compared with wild-type mice. $\alpha \mathrm{B}$-crystallin was prominently expressed in subretinal fibrotic lesions in mice. In vitro, overexpression of $\alpha \mathrm{B}$-crystallin induced EMT, whereas suppression of $\alpha \mathrm{B}$-crystallin induced a mesenchymal-epithelial transition. Transforming growth factor- $\beta 2$-induced EMT was further enhanced by overexpression of $\alpha \mathrm{B}$-crystallin but was inhibited by suppression of $\alpha B$-crystallin. Silencing of $\alpha B$-crystallin inhibited multiple fibrotic processes, including cell proliferation, migration, and fibronectin production. Bone morphogenetic protein 4 upregulated $\alpha \mathrm{B}$-crystallin, and its EMT induction was inhibited by knockdown of $\alpha \mathrm{B}$-crystallin. Furthermore, inhibition of $\alpha B$-crystallin enhanced monotetraubiquitination of SMAD4, which can impair its nuclear localization. Overexpression of $\alpha \mathrm{B}$-crystallin enhanced nuclear translocation and accumulation of SMAD4 and SMAD5. Thus, $\alpha \mathrm{B}$-crystallin is an important regulator of EMT, acting as a molecular chaperone for SMAD4 and as its potential therapeutic target for preventing subretinal fibrosis development in neovascular age-related macular degeneration. (Am J Pathol 2016, 186: 859-873; http:// dx.doi.org/10.1016/j.ajpath.2015.11.014)
\end{abstract}

Age-related macular degeneration (AMD) is a leading cause of blindness because of progressive degeneration of the macular region of the retina that is responsible for visual acuity and color vision. The natural history of AMD is a progression from its early stage to the two forms of late stage of AMD: geographic atrophy and neovascular AMD (nAMD). ${ }^{1}$

The visual prognosis for nAMD is poor; the condition progresses rapidly with the development of choroidal neovascularization (CNV) and subsequent subretinal fibrosis. Although the commonly used treatment with anti-vascular endothelial growth factor (VEGF) drugs improves visual acuity in nAMD patients, the subretinal scarring (fibrosis) that may develop in approximately half of all anti-VEGF-treated eyes within 2 years has been identified as a cause of unsuccessful outcomes. ${ }^{2}$ Thus, therapeutic strategies for the inhibition of subretinal fibrosis are currently an active area of investigation. Among the critical growth factors involved in subretinal fibrosis, platelet-derived growth factor (PDGF) is a potential therapeutic target. Currently, several clinical trials for the treatment for nAMD have been evaluating the

Supported by NIH grants EY03040 and EY01545, the Arnold and Mabe Beckman Foundation, the Japanese Society for the Promotion of Science, and a Japan Society for the Promotion of Science Postdoctoral Fellowships for Research Abroad fellowship (K.I.).

R.K. and D.R.H. contributed equally to this work as senior authors.

Disclosures: None declared.

Current address of K.I., Department of Ophthalmology, Kyushu University Graduate School of Medical Sciences, Fukuoka, Japan. 
efficacy of dual VEGF/PDGF inhibitors, such as the following: E10030 (Ophthotech, New York, NY), an antiPDGF pegylated aptamer as an adjunct to anti-VEGF therapy; sorafenib, an inhibitor of VEGF receptor, PDGF receptor, and Raf kinases; and pazopanib, an inhibitor of VEGF receptor, PDGF receptor, and c-kit. ${ }^{3}$ In addition, it has been shown that nucleotide-binding oligomerization domain-, leucine-rich repeat domain-, and pyrin domain-containing 3 inflammasome activation is implicated in the pathogenesis of nAMD. ${ }^{4}$ The recent implication of inflammasome activation in the pathogenesis of hepatic fibrosis ${ }^{5}$ suggests that the inflammasome should be further evaluated for its potential role in subretinal fibrosis. Important inflammasome effector cytokines, IL-1 $\beta$ and IL-18, can be potential therapeutic targets for the treatment of subretinal fibrosis in nAMD. In support of this contention, inhibition of IL- $1 \beta$ has been shown to inhibit the development of experimental CNV in mice. ${ }^{6}$

Subretinal fibrosis results from an excessive wound healing response, characterized by fibrous membrane formation after CNV. In fibrous membranes, the main cellular components are myofibroblasts, the cells immunoreactive for $\alpha$-smooth muscle actin ( $\alpha$-SMA). Previous histological studies imply that the source of myofibroblasts can be both bone marrow-derived cells and retinal pigment epithelium (RPE) cells. ${ }^{7,8}$ After injury to RPE, the cells undergo epithelial-mesenchymal transition (EMT), which enables transdifferentiation, resulting in the conversion of epithelial cells to myofibroblasts. CNV induction can result in the recruitment of more inflammatory cells and fibroblasts, which can be a direct or indirect source of additional myofibroblasts. Myofibroblasts play important roles in the development of subretinal fibrosis, such as proliferation, migration, and extracellular matrix remodeling. ${ }^{8}$ Although previous studies have indicated the involvement of several growth factors and cytokines in $\mathrm{EMT}^{8},{ }^{\text {the }}$ precise molecular mechanism and the critical regulators of this process remain to be determined.

The soluble cytoplasmic protein $\alpha \mathrm{B}$-crystallin is a prominent member of the small heat shock protein family. The small heat shock proteins exert diverse biological activities in both normal and stressed cells. They can act as molecular chaperones by binding misfolded proteins to prevent their denaturation and aggregation. ${ }^{9} \alpha \mathrm{B}$-crystallin can bind to and stabilize cytoskeleton proteins, such as desmin and actin, and help to maintain cytoskeletal integrity. ${ }^{10}$ The role of $\alpha \mathrm{B}$-crystallin in EMT in liver and lung fibrosis has been recently reported. ${ }^{11,12}$

Our previous work has suggested an important role for $\alpha \mathrm{B}$-crystallin in both the early and late stages of AMD. The early stage of AMD is characterized by the accumulation of drusen between the RPE and Bruch's membrane, accompanied by RPE cell death and synaptic dysfunction. ${ }^{13}$ Geographic atrophy is caused by extensive atrophy and loss of the RPE and the overlying photoreceptors that rely on the RPE for trophic support. ${ }^{1} \alpha \mathrm{B}$-crystallin can be seen in RPE, associated with drusen and identified as one of the components of drusen. ${ }^{14-16}$ Our laboratory has shown that RPE cells lacking $\alpha \mathrm{B}$-crystallin are more susceptible to oxidative and endoplasmic reticulum stress compared with normal RPE. ${ }^{17-20}$ Furthermore, RPE-overexpressing $\alpha \mathrm{B}$-crystallin shows resistance to apoptosis. ${ }^{21}$ These findings suggest that $\alpha \mathrm{B}$-crystallin plays a cytoprotective role against multiple stress stimuli that can cause RPE cell death, resulting in drusen formation and geographic atrophy. In addition, we previously demonstrated that $\alpha \mathrm{B}$-crystallin plays a regulatory role by functioning as a chaperone for VEGF in ocular angiogenesis and may play a part in $\mathrm{CNV}$ formation in nAMD. ${ }^{22}$ However, the involvement of $\alpha \mathrm{B}$-crystallin in subretinal fibrosis in nAMD has not been studied.

Herein, we examined the pathogenesis of subretinal fibrosis in $\alpha \mathrm{B}$-crystallin ${ }^{-1-}$ and wild-type (WT) mice; we further investigated the role of $\alpha \mathrm{B}$-crystallin in EMT and fibrotic process in cultured RPE cells.

\section{Materials and Methods}

\section{Study Approval}

All procedures used in these studies were conducted in accordance with applicable regulatory guidelines at the University of Southern California (Los Angeles, CA), principles of human research subject protection in the Declaration of Helsinki, and principles of animal research in the Association for Research in Vision and Ophthalmology Statement for the Use of Animals in Ophthalmic and Vision Research. Human fetal eyes (16 to 18 weeks of gestation) were obtained from Advanced Bioscience Resources Inc. (Alameda, CA) and Novogenix Laboratories LLC (Los Angeles, CA), and written informed consent was obtained from all donors.

\section{RPE Cell Culture}

Human RPE cells were isolated from human fetal eyes (gestational age, 16 to 18 weeks) obtained from Advanced Bioscience Resources Inc. and Novogenix Laboratories LLC. Primary cultures of RPE cells were established, as described previously. ${ }^{23}$ The experiments used cultured RPE cells at two to four passages with normal morphology.

\section{Mice}

$\alpha \mathrm{B}$-crystallin ${ }^{-1-}$ mice on the 129 S6/SvEvTac background were generated at the National Eye Institute (Bethesda, MD). ${ }^{24}$ The 129 S6/SvEvTac WT mice were purchased from Taconic Farms (Germantown, NY). Male mice, aged between 6 and 8 weeks, were used in all studies to eliminate sex-related bias in size of laserinduced CNV lesions. ${ }^{25}$ 
Table 1 SiRNA Sequences

\begin{tabular}{|c|c|}
\hline$\alpha \mathrm{B}$-crystallin & $\begin{array}{l}\text { S r } r\left(5^{\prime}-\text { CCAGGGAGUUCCACAGGAA-3') dTdT }\right. \\
\text { AS } r\left(5^{\prime}-\text { UUCCUGUGGAACUCCCUGG-3 } 3^{\prime}\right) \text { dTdT }\end{array}$ \\
\hline $\begin{array}{l}\text { Scrambled } \\
\text { control }\end{array}$ & $\begin{array}{l}S r\left(5^{\prime}-\text { UUCUCCGAACGUGUCACGU-3 } 3^{\prime}\right) d T d T \\
\text { AS } r\left(5^{\prime}-\text { ACGUGACACGUUCGGAGAA- } 3^{\prime}\right) d T d T\end{array}$ \\
\hline
\end{tabular}

AS, antisense; $S$, sense.

\section{Laser-Induced CNV}

$\mathrm{CNVs}$ were generated as described previously. ${ }^{22}$ Briefly, laser photocoagulation $(532 \mathrm{~nm}, 150 \mathrm{~mW}, 50$ milliseconds, $75 \mu \mathrm{m})$ was applied to each fundus using a coverslip as a contact lens on day 0 . We made four laser spots per eye for immunohistochemistry and 20 laser spots for extracting protein for enzyme-linked immunosorbent assay (ELISA) analysis. The production of a subretinal bubble at the time of laser application indicated a rupture of Bruch's membrane. We excluded animals that developed burns with bleeding.

\section{CNV and Choroidal Fibrosis Volume Measurement}

The volumes of the CNV and choroidal fibrous tissue were measured in choroidal flat mounts on days 7, 21, and 35 after laser photocoagulation. Mouse eye cups were fixed in $4 \%$ paraformaldehyde and then permeabilized in $1 \%$ Triton X-100 (ICN Biomedicals, Irvine, CA) for 2 hours. After removal of the anterior segment and neural retina, fluoresceinlabeled isolectin-B4 (Vector Laboratories, Burlingame, CA) and collagen type I antibody (Rockland Immunochemicals Inc., Limerick, PA) were added to the mouse eye cup and incubated at $4{ }^{\circ} \mathrm{C}$ overnight to detect $\mathrm{CNV}$ and choroidal fibrous tissue, respectively. The secondary antibody against collagen type I was goat anti-rabbit IgG secondary antibody, Alexa Fluor 647 conjugate (Life Technologies, Grand Island, NY). Samples were coverslipped with Vectashield medium (Vector Laboratories) and examined by use of the Perkin Elmer spinning disk confocal microscope (Perkin Elmer, Waltham, MA). Fluorescence volume measurements were recorded by generating image stacks of optical slices within lesions, as previously described. $^{26}$

\section{ELISA}

Total protein was isolated from the sonicated mouse RPEchoroid complexes using tissue protein extraction reagent with protease inhibitor (Thermo Scientific, Waltham, MA). Each experiment, consisting of two pooled RPEchoroid complexes, was performed in triplicate (biological replicates). The concentrations of $\alpha \mathrm{B}$-crystallin and bone morphogenetic protein 4 (BMP4) in the mouse RPE-choroid complexes were measured with ImmunoSet $\alpha \mathrm{B}$-Crystallin ELISA kit (ENZO Life Sciences, Farmingdale, NY) and BMP4 BioAssay ELISA Kit (US Biological, Salem, MA), respectively, according to the manufacturer's instructions.

\section{Transfection}

RPE cells were cultured for 24 hours in 6- or 12-well plates or 4-well chamber slides to a confluence of $70 \%$ to $90 \%$. siRNA targeting $\alpha \mathrm{B}$-crystallin or control siRNA (Qiagen, Valencia, CA) (sequences included in Table 1) were mixed

Table 2 List of Antibodies Used in This Study

\begin{tabular}{llll}
\hline Target molecule & Antibody type & Application & Source \\
\hline Human $\alpha$ B-crystallin & Mouse monoclonal & WB, IHC & ENZ0 Life Sciences \\
Mouse $\alpha$ B-crystallin & Rabbit polyclonal & IHC & ENZO Life Sciences \\
Pan-cytokeratin & Mouse monoclonal & IHC & Santa Cruz Biotechnology (Dallas, TX) \\
$\alpha$-SMA & Mouse monoclonal & WB, IHC & Sigma-Aldrich (St. Louis, M0) \\
E-cadherin (24E10) & Rabbit monoclonal & WB, IHC & Cell Signaling \\
SNAIL & Rabbit polyclonal & WB & Abgent (San Diego, CA) \\
SLUG & Rabbit polyclonal & WB & Santa Cruz Biotechnology \\
SMAD4 & Rabbit polyclonal & IHC & Santa Cruz Biotechnology \\
SMAD5 & Rabbit polyclonal & WB & Cell Signaling \\
SMAD2/3 & Rabbit polyclonal & WB & Cell Signaling \\
$\beta$-Catenin & Rabbit monoclonal & WB & Cell Signaling \\
NF-KB p65 & Rabbit monoclonal & WB & Cell Signaling \\
Notch2 & Rabbit monoclonal & WB & Cell Signaling \\
Fibronectin & Mouse monoclonal & IHC & R\&D Systems \\
Collagen type I & Rabbit polyclonal & WB, IHC & Rockland Immunochemicals \\
Ubiquitin & Rabbit polyclonal & WB & Thermo Scientific \\
Histone H3 & Rabbit monoclonal & WB & Cell Signaling \\
GAPDH & Mouse monoclonal & WB & EMD Millipore (Billerica, MA) \\
$\beta$-Actin & Mouse monoclonal & WB & Santa Cruz Biotechnology \\
\hline
\end{tabular}

$\alpha$-SMA, $\alpha$-smooth muscle actin; GAPDH, glyceraldehyde-3-phosphate dehydrogenase; IHC, immunohistochemistry; WB, Western blotting. 
Table 3 Primer Sequences Used for Real-Time RT-PCR

\begin{tabular}{lll}
\hline Target molecule & Forward primer sequence & Reverse primer sequence \\
\hline$\alpha B-c r y s t a l l i n$ & $5^{\prime}$-TCCCCAGAGGAACTCAAAGTTAAG-3' & $5^{\prime}$-GGCGCTCTTCATGTTTCCA-3' \\
$\alpha$-SMA & $5^{\prime}$-TCTGTAAGGCCGGCTTTGC-3' & $5^{\prime}-$ TGTCCCATTCCCACCATCA-3' \\
E-cadherin & $5^{\prime}$-ATTTTTCCCTCGACACCCGAT-3' & $5^{\prime}-$ TCCCAGGCGTAGACCAAGA-3' \\
SNAIL & $5^{\prime}$-TCGGAAGCCTAACTACAGCGA-3' & $5^{\prime}$-AGATGAGCATTGGCAGCGAG-3' \\
SLUG & $5^{\prime}$-CGAACTGGACACACATACAGTG-3' & $5^{\prime}$-CTGAGGATCTCTGGTTGTGGT-3' \\
GAPDH & $5^{\prime}$-ACAGTCGCCGCATCTTCTT-3' & $5^{\prime}$-ACGACCAAATCCGTTGACTC-3' \\
\hline
\end{tabular}

$\alpha$-SMA, $\alpha$-smooth muscle actin; GAPDH, glyceraldehyde-3-phosphate dehydrogenase.

(10 nmol/L at final concentration) with RNA transfection reagent (Lipofectamine RNAiMAX; Life Technologies). To overexpress $\alpha \mathrm{B}$-crystallin, pCMV6-XL5 plasmid encoding human $\alpha \mathrm{B}$-crystallin (OriGene Technologies, Rockville, MD) or empty vector was mixed with Lipofectamine LTX (Life Technologies) or X-tremeGENE DNA (Roche Applied Science, Indianapolis, IN), following the manufacturer's protocol. Twenty-four hours after transfection, the composite transfection mixture was removed and replaced with Dulbecco's modified Eagle's medium containing 3\% fetal bovine serum or serum-free medium for 24 hours, followed with recombinant transforming growth factor (TGF)- $\beta 2$ (Sigma-Aldrich, St. Louis, MO) or BMP4 (R\&D Systems, Minneapolis, MN) treatment before each assay.

\section{Western Blot Analysis}

Western blot analysis was performed as described previously. ${ }^{17}$ After a 48-hour incubation in medium with or without recombinant TGF- $\beta 2$ or BMP4, total cell lysates were extracted with lysis buffer. In separate experiments, empty vector or $\alpha \mathrm{B}$-crystallin transfected cells were treated with $10 \mathrm{ng}$ TGF- $\beta 2$ for 2 hours and nuclear and cytosolic fractions were separated. The fractionation of the cells into cytosolic and nuclear fractions was performed using a nuclear/cytosol fractionation kit (BioVision, Milpitas, CA). The extracted cell lysates were subjected to Tris- $\mathrm{HCl}$ polyacrylamide gels, and the blots were incubated with antibodies (Abs) (Table 2) and visualized using an enhanced chemiluminescence (Amersham Pharmacia Biotech, Cleveland, $\mathrm{OH}$ ) detection system. Glyceraldehyde-3-phosphate dehydrogenase or histone $\mathrm{H} 3$ was used as the loading control.

\section{RNA Isolation and Real-Time Quantitative RT-PCR}

Total RNA was isolated from cells using the RNeasy kit (Qiagen), according to the manufacturer's instructions. Realtime quantitative RT-PCR was performed, as described previously. $^{22}$ To eliminate contamination of genomic or plasmid DNA, we pretreated total RNA with DNase (Life Technologies) before proceeding to reverse transcription. The primer sequences are shown in Table 3. Gene expression levels were normalized relative to glyceraldehyde-3phosphate dehydrogenase mRNA and reported as foldchange over controls.
Immunohistochemistry and Immunofluorescence Staining

RPE cells were cultured in 4-well multichamber slides (Thermo Scientific) in serum-free medium for 12 hours and then stimulated with recombinant TGF- $\beta 2$ for up to 2 days. The cells were rinsed in phosphate-buffered saline (PBS) for 3 minutes and fixed and permeabilized with ice-cold methanol for 20 minutes. After a 30minute blocking step with $10 \%$ goat serum, the cells were incubated with primary Abs (Table 2) for 24 hours at $4^{\circ} \mathrm{C}$ and then incubated with secondary Abs. Cryostat sections ( $6 \mu \mathrm{m}$ thick) of snap-frozen mouse eyes were obtained from four WT mice and four $\alpha \mathrm{B}$-crystallin ${ }^{-1-}$ mice. For immunohistochemistry, the sections were treated with $0.3 \%$ hydrogen peroxide for 10 minutes to block endogenous peroxide. The sections were then blocked in $10 \%$ normal goat serum for 30 minutes and incubated with Abs (Table 2) overnight at $4^{\circ} \mathrm{C}$. Slides were washed with PBS and incubated with biotinylated IgG (Vector Laboratories) for 1 hour. Immunoperoxidase was detected with aminoethylcarbazole as the chromogen, using an aminoethylcarbazole kit (Life Technologies), according to the manufacturer's protocol. Immunofluorescence staining for the sections was performed as described previously. ${ }^{22}$ Pan-cytokeratin-positive cells or cells positive for $\alpha$-SMA or E-cadherin were calculated as the number of the immunoreactive cells per $\mathrm{mm}^{2}$ of CNV area at day 35 after laser, according to the method previously reported. ${ }^{7}$ The average percentage of the cells immunoreactive for $\alpha$-SMA or E-cadherin in pan-cytokeratin-positive cells was calculated from four eyes. The specimens were mounted in mounting medium, including DAPI (Vector Laboratories), and examined with a Perkin Elmer spinning disk confocal microscope.

\section{Immunofluorescence Localization of SMAD4 and SMAD5}

RPE cells transfected with empty vector or vector with $\alpha B$-crystallin grown on 4-well chamber slides were serum starved overnight and then treated with $10 \mathrm{ng} / \mathrm{mL}$ TGF- $\beta 2$ for 2 hours in serum-free medium. After treatment, cells were washed, fixed in $4 \%$ paraformaldehyde, blocked in $5 \%$ goat serum, and incubated with primary antibody for anti-rabbit SMAD4 or anti-rabbit SMAD5 (1:100 dilution; 
A
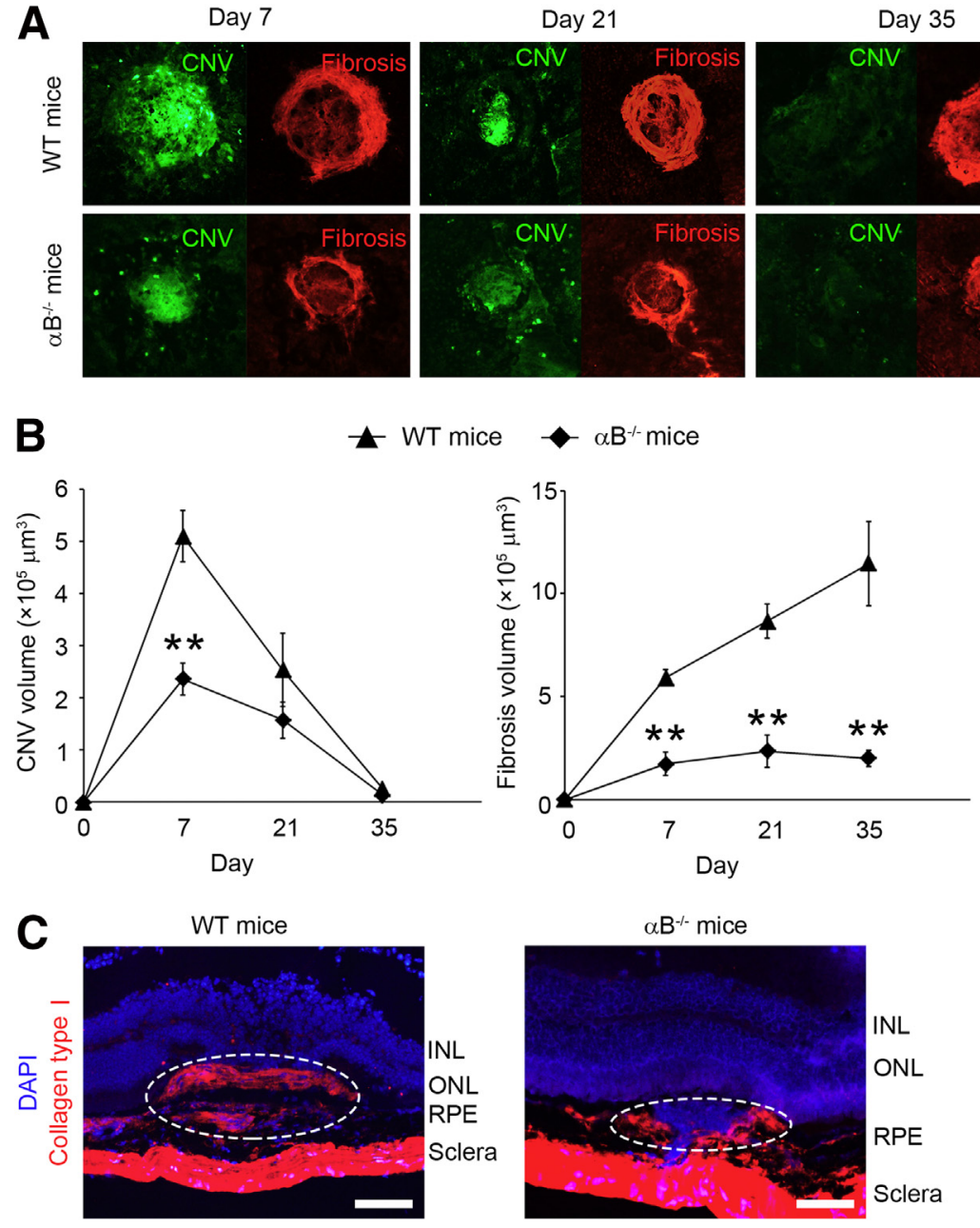

Day 35

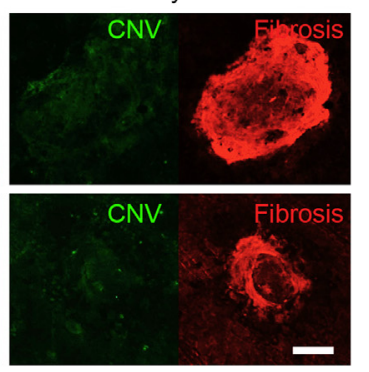

Figure $1 \quad \alpha \mathrm{B}$-crystallin $(\alpha \mathrm{B})$ knockout (K0; $\alpha \mathrm{B}^{-/-}$) mice have less subretinal fibrosis development after laser injury. Wild-type (WT) and $\alpha \mathrm{B}^{-1-}$ mice had laser photocoagulation (four lesions per eye) on day 0. A: Representative images of choroidal neovascularization (CNV; stained by isolectin B4) and fibrosis (stained by collagen type I) at days 7, 21, and 35 after laser in WT and $\alpha \mathrm{B}^{-1-}$ mice. B: The mean volume of the CNV and fibrosis at days 7, 21, and 35 after laser. C: Histological section through a CNV membrane at day 35 after laser in WT and $\alpha \mathrm{B}^{-/-}$mice. Fibrous tissue can be seen (dotted circles) in the subretinal space. ${ }^{* *} P<0.01$. $n=8$ per group (B). Scale bars: $100 \mu \mathrm{m}$ (A); $50 \mu \mathrm{m}$ (C). INL, inner nuclear layer; $0 \mathrm{NL}$, outer nuclear layer; RPE, retinal pigment epithelium.
Cell Signaling Technology, Danvers, MA) overnight at $4^{\circ} \mathrm{C}$. Cells were washed in PBS, incubated with fluorescein isothiocyanate-conjugated anti-rabbit secondary antibody, mounted with DAPI-containing medium (Vector Laboratories), and viewed with a spinning disk confocal microscope.

\section{Isolation of Ubiquitin Conjugates}

Monotetraubiquitin- and polyubiquitin-conjugated protein was isolated from cultured RPE using the Pierce Ubiquitin Enrichment kit (Thermo Scientific). Briefly, $150 \mu \mathrm{L}$ of cell lysates $(1 \mathrm{mg} / \mathrm{mL})$ was applied to $150 \mu \mathrm{L}$ of sample dilution buffer and $20 \mu \mathrm{L}$ of ubiquitin affinity resin. The mixtures were incubated at $4{ }^{\circ} \mathrm{C}$ overnight and then centrifuged using a spin column. A resin in this spin column binds polyubiquitin containing four or more ubiquitin subunits. Thus, the flow-through is harvested as monotetraubiquitin-conjugated protein, whereas the polyubiquitinated proteins were recovered in the elution buffer. Laemmli sample buffer (Bio-Rad Laboratories Inc., Irvine, CA) was added to the column and heated at $95^{\circ} \mathrm{C}$ for 5 minutes.

\section{Cell Proliferation Assay}

Proliferation in RPE cells was measured using 5-bromo-2'deoxyuridine ELISA (Roche Applied Science), according to the manufacturer's instructions, with a 2-hour 5-bromo-2'deoxyuridine incubation.

\section{Cell Migration Assay}

A cell migration assay was performed using an Oris 96-well cell migration assay kit (Platypus Technologies, Madison, WI), according to the manufacturer's instructions, as described previously. ${ }^{27}$ Briefly, $5 \times 10^{4}$ cells were seeded in each well and transfected with or without siRNAs. After 1 hour of pretreatment with Dulbecco's modified Eagle's medium with $3 \%$ fetal bovine serum containing recombinant TGF- $\beta 2$ with $5 \mu \mathrm{mol} / \mathrm{L}$ aphidicolin (Sigma-Aldrich) to inhibit cell division, the stoppers were removed to allow cells to migrate into the detection zone. The cells were incubated for 48 hours after initiating migration and stained with PBS containing calcein AM (Life Technologies) for 1 hour. The area of cell migration was determined using Photoshop software version CS3 (Adobe Systems, San Jose, CA). 
A

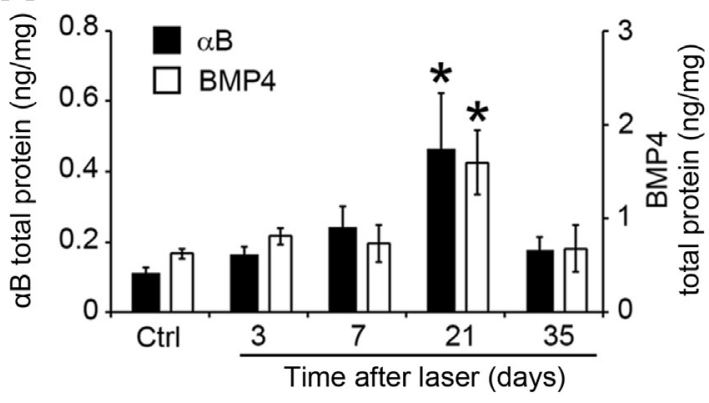

C
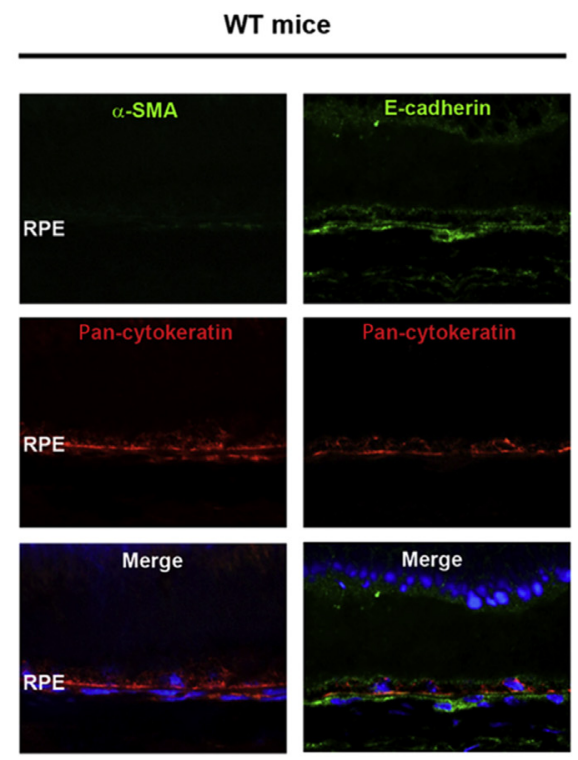

D

WT mice at day 35 after laser
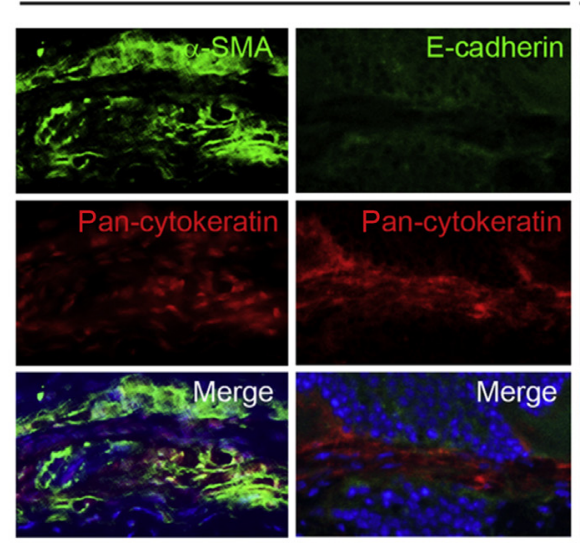

E
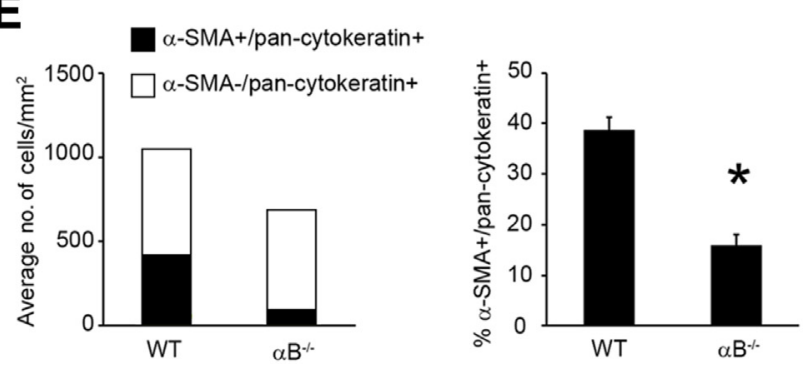

B

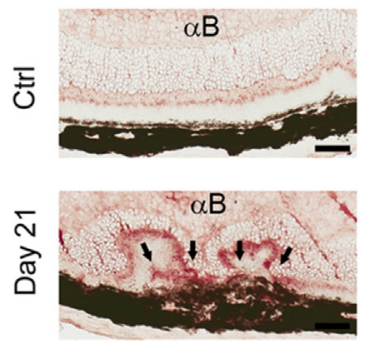

$\alpha B-/-$ mice
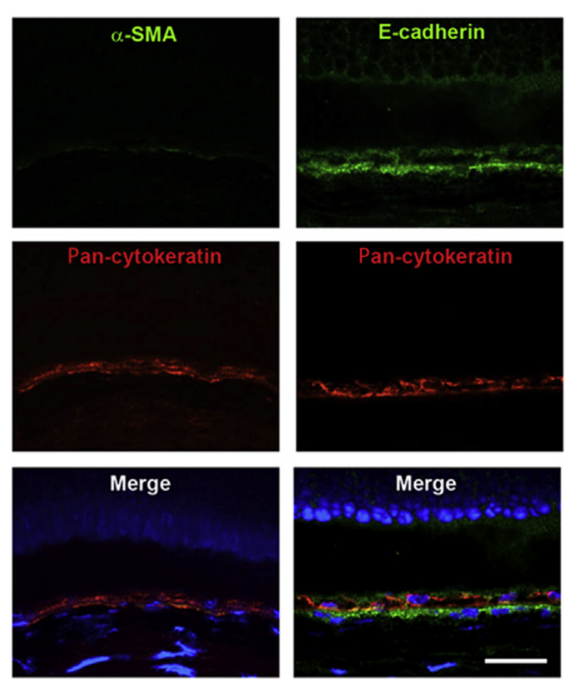

$\alpha \mathrm{B}^{-/-}$mice at day 35 after laser
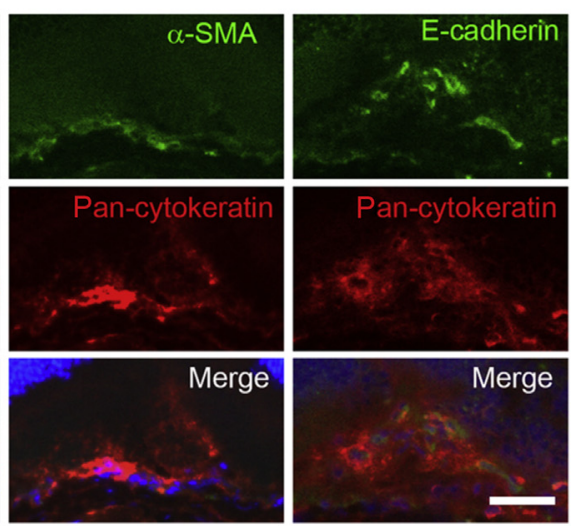

$\mathbf{F}$

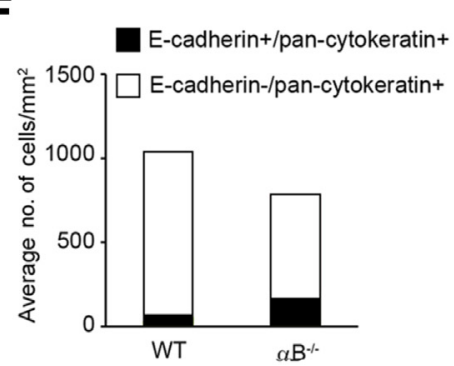

Figure $2 \alpha B$-crystallin $(\alpha B)$ is upregulated and has an impact on epithelialmesenchymal transition markers in retinal pigment epithelium (RPE) cells in subretinal fibrous tissue. $A$ : Levels of $\alpha B$ and bone morphogenetic protein (BMP)- 4 in protein extracted from the RPE-choroidal complexes after 20 laser lesions. B: Histological section of the choroidal neovascularization (CNV) membrane at day 21 after laser. Immunoreactivity to $\alpha \mathrm{B}$ can be seen in the subretinal space (arrows). $C$ and D: Triple immunofluorescence staining for $\alpha$-smooth muscle actin ( $\alpha$-SMA; mesenchymal marker), E-cadherin (epithelial marker), and pan-cytokeratin (a marker for RPE cells) in eyes without laser treatment (C) and eyes with subretinal fibrosis (D) of wild-type (WT) and $\alpha \mathrm{B}$ knockout (KO; $\alpha \mathrm{B}^{-/-}$) mice. Nuclei are counterstained with DAPI (blue). E: Bar graph shows average number of cells immunoreactive for both $\alpha$-SMA and pan-cytokeratin and average number of the cells solely immunoreactive for pan-cytokeratin in the subretinal lesion. The proportions of cells immunoreactive for $\alpha$-SMA in the cells immunoreactive for pancytokeratin are calculated in the eyes of WT and $\alpha \mathrm{B}^{-/-}$mice at day 35 after laser. F: Bar graph shows average number of the cells immunoreactive for both E-cadherin and pan-cytokeratin and average number of cells solely immunoreactive for pancytokeratin is in the subretinal lesion. The proportions of cells immunoreactive for E-cadherin in the cells immunoreactive for pan-cytokeratin are calculated in the eyes of WT and $\alpha \mathrm{B}^{-1-}$ mice at day 35 after laser. ${ }^{*} P<0.05$ versus control (Ctrl) without laser treatment. $n=3$ per group (A); $n=4$ per group (E and F). Scale bars: $50 \mu \mathrm{m}$ (B); $100 \mu \mathrm{m}$ (C and D). 


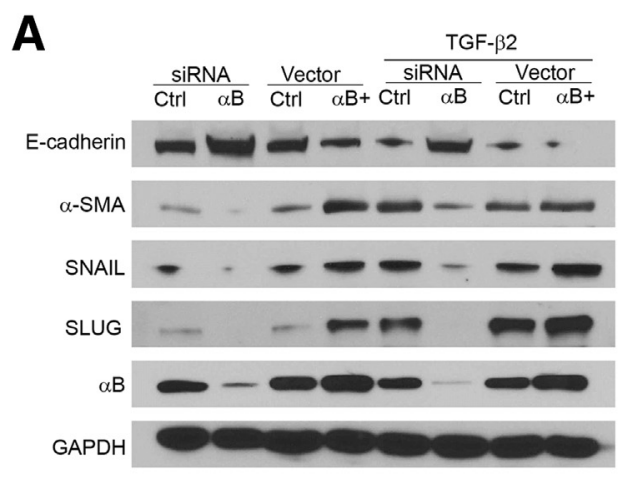

B
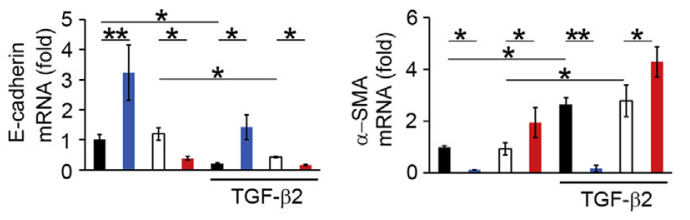

$$
\begin{aligned}
& \text { Ctrl siRNA } \\
& \alpha \mathrm{B} \text { siRNA } \\
& \square \text { Ctrl vector } \\
& \alpha \mathrm{B}+\text { vector }
\end{aligned}
$$

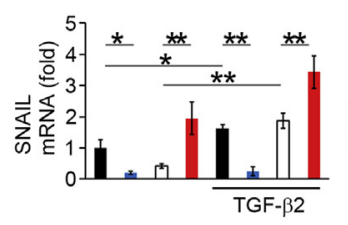

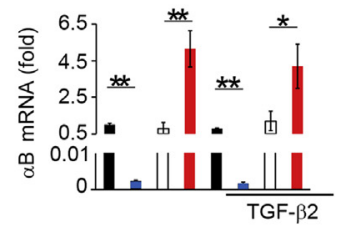

C

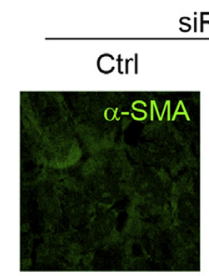

SiRNA
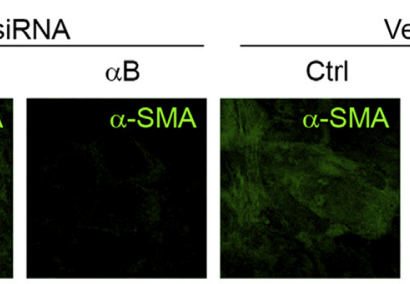

Vector

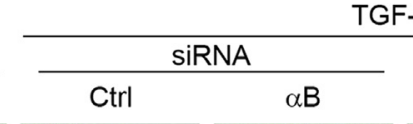

TGF- $\beta 2$
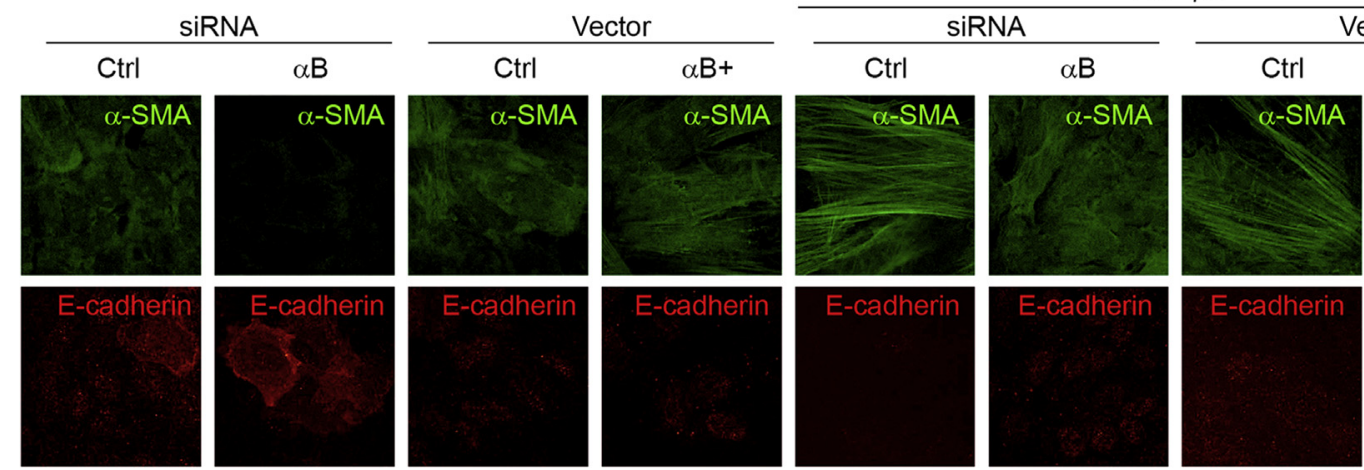

$\alpha \mathrm{B}+$
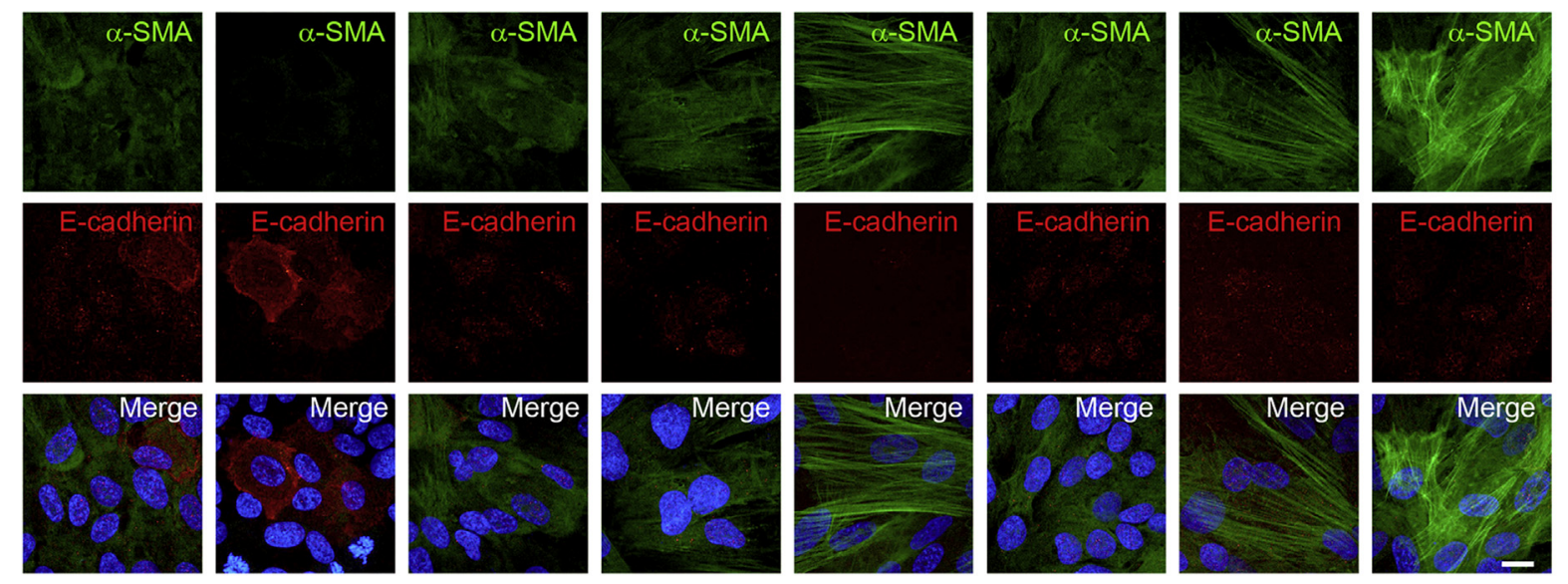

Figure $3 \alpha \mathrm{B}$-crystallin $(\alpha \mathrm{B})$ induces epithelial-mesenchymal transition through regulation of SNAIL and SLUG expression. After transfection with control (Ctrl) siRNA, $\alpha \mathrm{B}$-crystallin siRNA, empty (Ctrl) vector, and $\alpha \mathrm{B}$-encoding $\left(\alpha \mathrm{B}^{+}\right)$vector, retinal pigment epithelium (RPE) cells were stimulated with $10 \mathrm{ng} / \mathrm{mL}$ transforming growth factor (TGF)- $\beta 2$ for 48 hours. A: Western blot analysis of E-cadherin, $\alpha$-smooth muscle actin ( $\alpha$-SMA), SNAIL, SLUG, $\alpha B$, and glyceraldehyde-3-phosphate dehydrogenase (GAPDH) in the cell lysates of RPE cells. Quantification shown in Supplemental Figure S1. B: mRNA expression of E-cadherin, $\alpha$-SMA, SNAIL, SLUG, and $\alpha B$ is shown as relative fold to control siRNA normalized to GAPDH. C: Triple immunofluorescence staining for $\alpha$-SMA and E-cadherin in RPE cells. Nuclei are stained blue. Data are presented as means \pm SEM (B). $n=4$ per group (B). ${ }^{*} P<0.05$, ${ }^{*} P<0.01$. Scale bar $=10 \mu \mathrm{m}(\mathrm{C})$.

\section{Statistical Analysis}

All results are expressed as means \pm SEM. The statistical significance of differences between groups was analyzed using the Tukey's (honest significant difference) test or the two-tailed $t$-test. In comparison with the control group, Dunnett's $t$-test was applied. Differences were considered significant at $P<0.05$. Statistical analyses were performed using JMP version 7.0.1 (SAS Institute, Cary, NC).

\section{Results}

Attenuation of Subretinal Fibrosis in $\alpha \mathrm{B}$-Crystallin ${ }^{-/-}$ Mice

To evaluate a time-dependent alteration of CNV and fibrosis development after laser treatment, we labeled RPE/choroid flat mounts with Abs against isolectin B4 and collagen type I to represent $\mathrm{CNV}$ and fibrosis, respectively. $\mathrm{CNV}$ reaches a maximum on day 7; thereafter, it begins to regress, disappearing almost completely within 35 days after laser. Fibrosis continues to increase for up to 35 days after laser (Figure 1A). As shown previously, ${ }^{22} \mathrm{CNV}$ volume at day 7 after laser was reduced in $\alpha \mathrm{B}$-crystallin ${ }^{-1-}$ mice compared with the WT mice. At days 21 and 35 after laser, no significant difference was seen in CNV volume between WT and $\alpha \mathrm{B}$-crystallin ${ }^{-l-}$ mice. Fibrosis volume was significantly $(P<0.01)$ reduced in $\alpha \mathrm{B}$-crystallin ${ }^{-1-}$ mice compared with the WT at days 7, 21, and 35 after laser (Figure 1, A and B). In WT mice, prominent subretinal fibrosis was seen at 35 days after laser with extensive deposition of collagen type I in the lesions; however, fibrosis in $\alpha \mathrm{B}$-crystallin ${ }^{-/-}$mice was markedly reduced (Figure 1C). These findings demonstrated significant attenuation of subretinal fibrosis that occurs subsequent to $\mathrm{CNV}$ in $\alpha \mathrm{B}$-crystallin ${ }^{-1-}$ mice. 
A

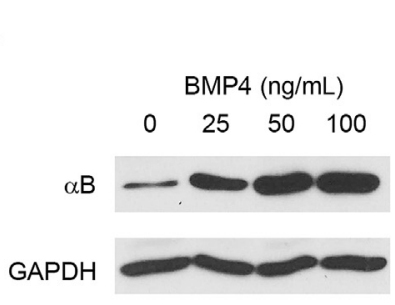

B

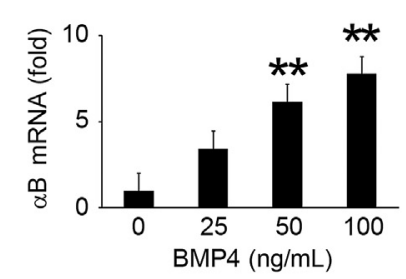

C

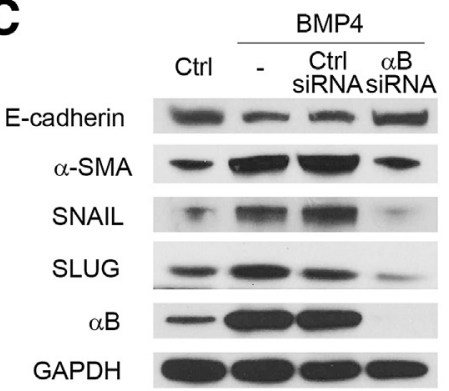

D
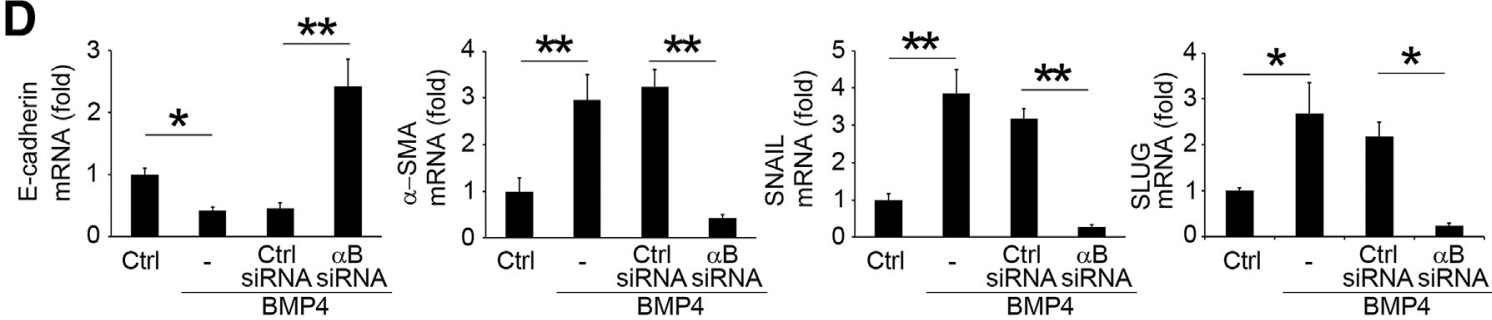

Figure 4 Bone morphogenetic protein (BMP)-4 induces epithelial-mesenchymal transition through up-regulation of $\alpha \mathrm{B}$-crystallin ( $\alpha \mathrm{B}$ ). A: Western blot analysis of $\alpha B$ and glyceraldehyde-3-phosphate dehydrogenase (GAPDH) in retinal pigment epithelium (RPE) cells stimulated with the indicated concentrations of BMP4 for 48 hours. Quantification shown in Supplemental Figure S2A. B: Expression of $\alpha$ B mRNA shown as relative fold to control (Ctrl) normalized to GAPDH. C: After transfection with control siRNA and $\alpha B$ siRNA, RPE cells were stimulated by $50 \mathrm{ng} / \mathrm{mL} B M P 4$ for 48 hours. Western blot analysis of Ecadherin, $\alpha$-smooth muscle actin $(\alpha$-SMA), SNAIL, SLUG, $\alpha$ B, and GAPDH in the cell lysates of RPE cells. Quantification shown in Supplemental Figure S2B. D: mRNA expression of E-cadherin, $\alpha$-SMA, SNAIL, SLUG, and $\alpha B$ shown as relative fold to control normalized to GAPDH. Data are presented as means \pm SEM (B and D). $n=4$ per group (B and D). ${ }^{*} P<0.05,{ }^{* *} P<0.01$.

\section{Impact of $\alpha \mathrm{B}$-Crystallin on EMT in Subretinal Fibrosis of Mouse Model}

BMP4, a member of the TGF- $\beta$ superfamily, is expressed in subretinal fibrosis lesions in AMD patients ${ }^{28}$ and up-regulates $\alpha \mathrm{B}$-crystallin in microvascular endothelial cells. ${ }^{29}$ To examine the expression changes of $\alpha \mathrm{B}$-crystallin and BMP4 in the development of subretinal fibrosis in mice, we measured $\alpha \mathrm{B}$-crystallin and BMP4 in the RPE-choroid complexes after laser injury of WT mice. ${ }^{30}$ The concentration of $\alpha \mathrm{B}$-crystallin and BMP4 gradually increased, peaking at day 21 after laser (Figure 2A). Prominent expression of $\alpha \mathrm{B}$-crystallin can be seen in the lesion at day 21 after laser, whereas expression of $\alpha \mathrm{B}$-crystallin was weak in control eyes (Figure 2B).

To investigate the difference in the cellular expression of EMT markers in the subretinal fibrosis lesion between WT and $\alpha \mathrm{B}$-crystallin ${ }^{-1-}$ mice, we stained the sections with Abs against $\alpha$-SMA (mesenchymal marker), E-cadherin (epithelial marker), and pan-cytokeratin (a marker for RPE cells). As a control, we evaluated expression of EMT-related markers in the RPE layer in mice without laser treatment. No significant difference was seen between WT and $\alpha \mathrm{B}$-crystallin ${ }^{-/-}$mice in the expression of EMT-related markers in RPE. In both WT and $\alpha \mathrm{B}$-crystallin ${ }^{-1}$ mice, RPE were positive for pan-cytokeratin and E-cadherin, but were negative for $\alpha$-SMA (Figure 2C). In the subretinal fibrosis lesions, RPE cells in WT mice expressed high levels of $\alpha$-SMA and low E-cadherin in the lesion at day 35 after laser. In contrast, RPE cells in $\alpha \mathrm{B}$-crystallin ${ }^{-/-}$mice expressed less $\alpha$-SMA and more E-cadherin compared with
WT mice (Figure 2D). Average numbers of RPE cells immunoreactive for $\alpha$-SMA were lower in $\alpha \mathrm{B}$-crystallin ${ }^{-1-}$ mice compared with WT mice. The proportion of the RPE cells immunoreactive for $\alpha$-SMA in the total RPE population was significantly reduced in $\alpha \mathrm{B}$-crystallin ${ }^{-1-}$ mice compared with WT mice (Figure 2E). Average numbers of RPE cells immunoreactive for E-cadherin were higher in $\alpha \mathrm{B}$-crystallin ${ }^{-1}$ mice compared with WT mice. The proportion of the RPE cells immunoreactive for E-cadherin in the total RPE population was significantly increased in $\alpha \mathrm{B}$-crystallin ${ }^{-1-}$ mice compared with WT mice (Figure 2F). Taken together, these findings indicate that in the absence of $\alpha \mathrm{B}$-crystallin, RPE in CNV lesions show a prominent inhibition of the EMT phenotype.

\section{$\alpha B$-Crystallin Induces EMT through Regulation of SNAIL and SLUG Expression}

To test whether modulation of $\alpha \mathrm{B}$-crystallin expression can change EMT in RPE cells, we examined the expression changes of E-cadherin, $\alpha$-SMA, SNAIL, and SLUG in RPE cells transfected with $\alpha \mathrm{B}$-crystallin siRNA and $\alpha \mathrm{B}$-crystallin-encoding vector. SNAIL and SLUG are transcription factors that can repress E-cadherin while stimulating $\alpha$-SMA ${ }^{31}$; SNAIL is known to be expressed in CNV membranes from patients with $n A M D$ and to induce EMT in RPE cells in vitro. ${ }^{32,33}$ TGF- $\beta 2$ is the predominant TGF- $\beta$ isoform in the posterior segment of the eye and a crucial EMT inducer for RPE cells. ${ }^{34}$ TGF- $\beta 2$ treatment at $10 \mathrm{ng} / \mathrm{mL}$ for 48 hours significantly reduced E-cadherin and increased $\alpha$-SMA, SNAIL, and SLUG but did not alter $\alpha \mathrm{B}$ crystallin at the protein or mRNA levels (Figure 3, A and B, and 

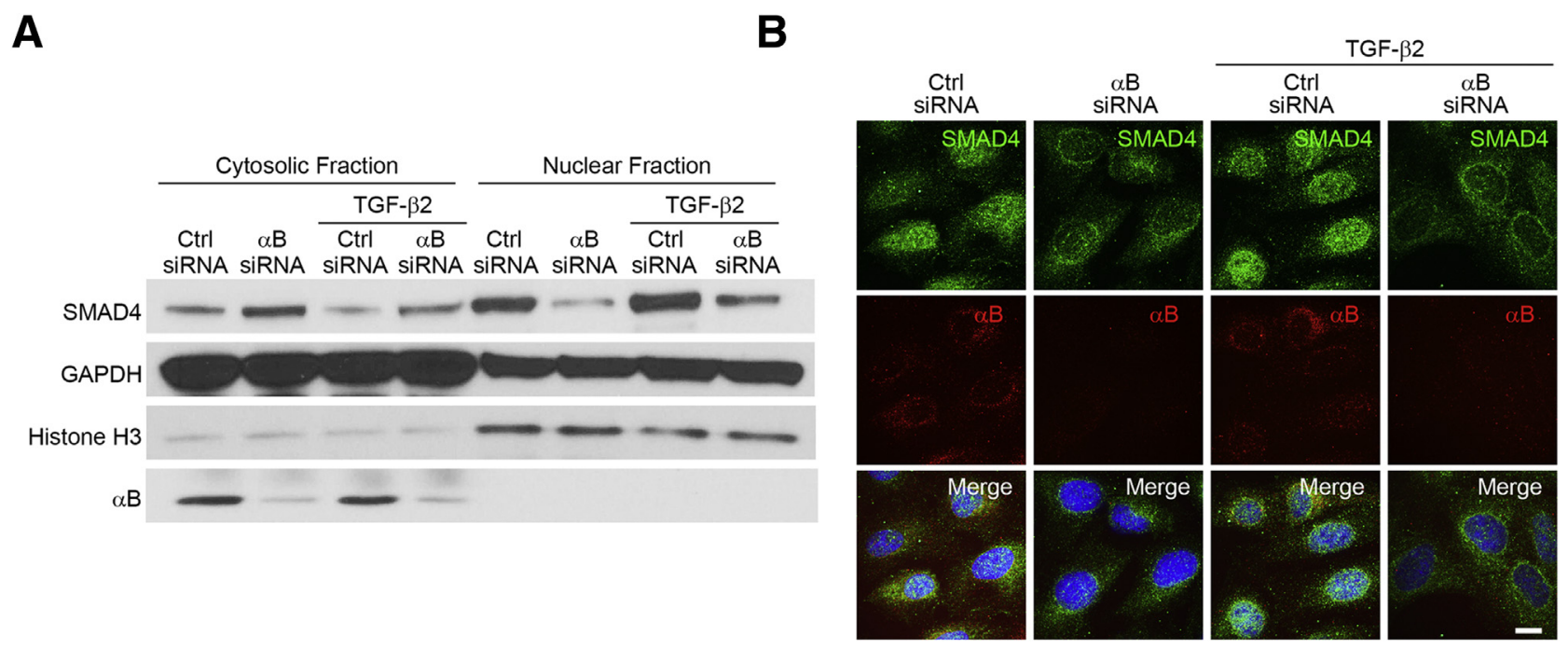

C

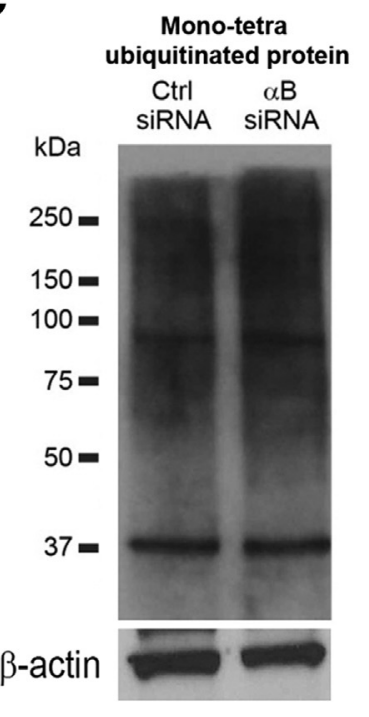

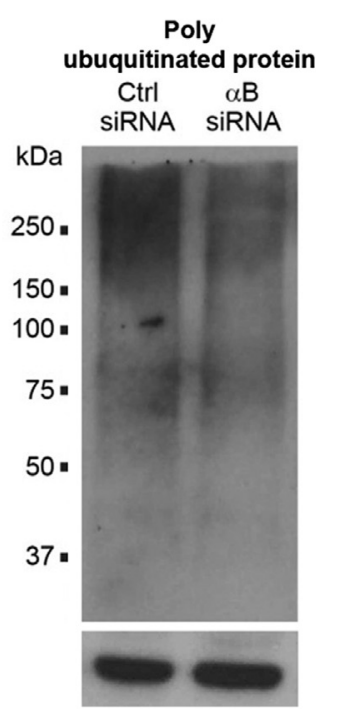

D
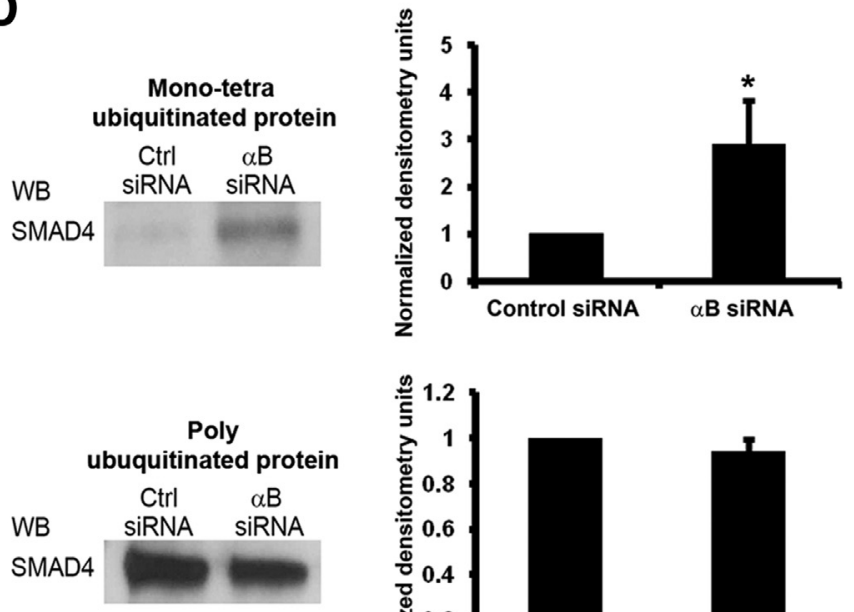

Figure $5 \quad \alpha \mathrm{B}$-crystallin $(\alpha \mathrm{B})$ silencing impairs nuclear translocation of SMAD4 mediated by its monotetraubiquitination. Retinal pigment epithelium (RPE) cells were transfected with control (Ctrl) siRNA and $\alpha B$ siRNA. A: Western blot (WB) analysis of SMAD4, glyceraldehyde-3-phosphate dehydrogenase (GAPDH; loading control for cytosolic protein), histone $\mathrm{H} 3$ (loading control for nuclear protein), and $\alpha \mathrm{B}$ in nuclear and cytoplasmic fractions extracted from RPE cells with or without $10 \mathrm{ng} / \mathrm{mL}$ transforming growth factor (TGF)- $\beta 2$ stimulation for 24 hours. B: Triple immunofluorescence staining for SMAD4 and $\alpha B$ in RPE cells, with or without 10 $\mathrm{ng} / \mathrm{mL}$ TGF- $\beta 2$ stimulation for 24 hours. Nuclei are counterstained with DAPI (blue). C: Western blot analysis of ubiquitin and $\beta$-actin in monotetraubiquitinated and polyubiquitinated protein isolated from RPE cells. D: Monotetraubiquitinated SMAD4 and polyubiquitinated SMAD4 detected by Western blot of ubiquitinated proteins; densitometric quantitation of blots from three independent experiments is shown. ${ }^{*} P<0.05$. Scale bar $=10 \mu \mathrm{m}(\mathbf{B})$.

Supplemental Figure S1). Suppression of $\alpha \mathrm{B}$-crystallin by siRNA significantly increased E-cadherin and decreased $\alpha$-SMA, SNAIL, and SLUG, whereas overexpression of $\alpha \mathrm{B}$-crystallin by DNA vector decreased E-cadherin and increased $\alpha$-SMA, SNAIL, and SLUG in protein and mRNA levels (Figure 3, A and B, and Supplemental Figure S1). The TGF- $\beta 2$-induced decrease of E-cadherin and the increase of $\alpha$ SMA, SNAIL, and SLUG could be inhibited by suppression of $\alpha \mathrm{B}$-crystallin and enhanced by overexpression of $\alpha \mathrm{B}$-crystallin (Figure 3, A and B, and Supplemental Figure S1). These results suggest that suppression of $\alpha \mathrm{B}$-crystallin induced a mesenchymal-epithelial transition (increased E-cadherin and decreased $\alpha$-SMA), whereas overexpression of $\alpha \mathrm{B}$-crystallin induced EMT (decreased E-cadherin and increased $\alpha$-SMA).
TGF- $\beta 2-$ induced EMT was inhibited by suppression of $\alpha \mathrm{B}$-crystallin.

Immunofluorescence staining validated the effect of $\alpha \mathrm{B}$-crystallin modulation on the expression changes of E-cadherin and $\alpha$-SMA, with or without TGF- $\beta 2$ treatment (Figure 3C). These results suggest that $\alpha \mathrm{B}$-crystallin plays a significant role in EMT of RPE cells.

\section{BMP4 Up-Regulates $\alpha \mathrm{B}$-Crystallin, Resulting in EMT}

Because BMP4 was induced in the CNV lesion after laser treatment in mice and up-regulates $\alpha \mathrm{B}$-crystallin in microvascular endothelial cells, ${ }^{29}$ we investigated whether BMP4 up-regulates $\alpha \mathrm{B}$-crystallin in RPE cells. Expression levels of 

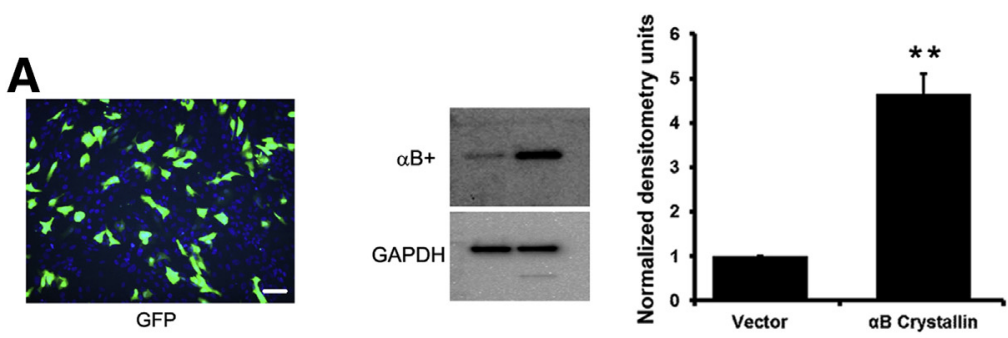

B
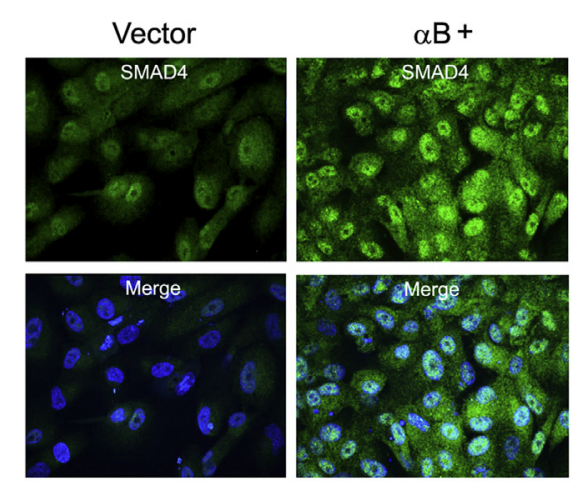

C

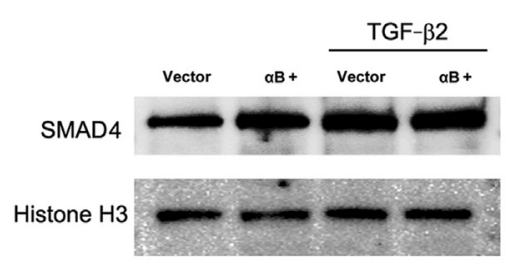

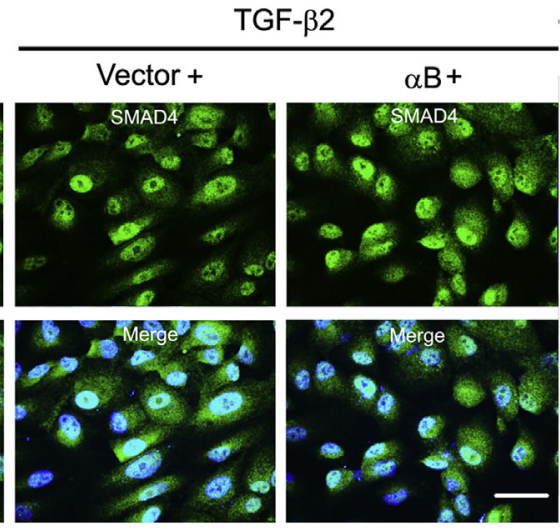

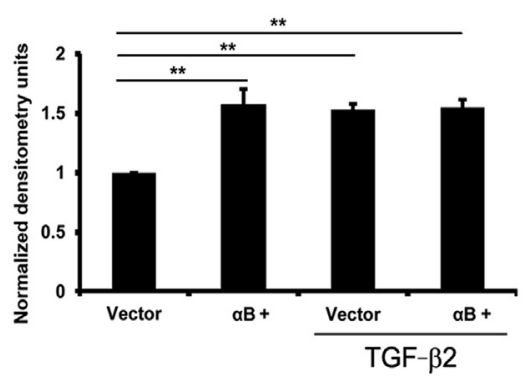

Figure $6 \quad \alpha \mathrm{B}$-crystallin $(\alpha \mathrm{B})$ overexpression increases nuclear translocation of SMAD4 in retinal pigment epithelium (RPE) cells. RPE cells were transfected with $\alpha \mathrm{B}$-encoding vector or empty vector, followed by treatment with $10 \mathrm{ng} / \mathrm{mL}$ transforming growth factor (TGF)- $\beta 2$ for 2 hours. A: RPE cells transfected with green fluorescent protein (GFP)-encoding plasmid using X-tremeGENE HP DNA transfection reagent showing transfection efficiency. Immunoblot analysis of $\alpha \mathrm{B}$ in vector-only and $\alpha \mathrm{B}$ transfected RPE cells; densitometric analysis of the blots from three independent experiments is shown. B: Immunofluorescence staining of SMAD4 in RPE cells transfected with empty vector or with $\alpha \mathrm{B}$ encoded vector. $\alpha B$ overexpression enhances nuclear expression of SMAD4. C: Immunoblot analysis of the nuclear fraction of SMAD4 after cell fractionation of RPE cells transfected with $\alpha B$ or empty vector; densitometric analysis of the blots from three independent experiments is shown. ${ }^{* *} P<0.01$. Scale bar $=25 \mu \mathrm{m}$ (A and B). GAPDH, glyceraldehye-3phosphate dehydrogenase. $\alpha \mathrm{B}$-crystallin protein and mRNA were strikingly upregulated at 48 hours after BMP4 stimulation at 25, 50, and $100 \mathrm{ng} / \mathrm{mL}$ in a dose-dependent manner (Figure 4, A and B, and Supplemental Figure S2A). BMP4 treatment (50 $\mathrm{ng} / \mathrm{mL}$ ) significantly reduced E-cadherin and increased $\alpha$-SMA, SNAIL, and SLUG in protein and mRNA levels; under these experimental conditions, $\alpha \mathrm{B}$-crystallin protein levels increased 4.5-fold. Next, we explored the potential role of $\alpha \mathrm{B}$-crystallin in BMP4-inducible EMT. We inhibited $\alpha \mathrm{B}$-crystallin expression by siRNA in RPE cells treated with BMP4. In $\alpha$ B-crystallin siRNA-transfected cells, BMP4-induced expression changes of E-cadherin, $\alpha$-SMA, SNAIL, and SLUG were inhibited at the protein and mRNA levels (Figure 4, C and D, and Supplemental Figure S2B). These findings indicate that BMP4 up-regulates $\alpha \mathrm{B}$-crystallin, resulting in the induction of EMT in RPE cells.

\section{Suppression of $\alpha \mathrm{B}$-Crystallin Inhibits Nuclear Translocation of SMAD4 Mediated by Its Monotetraubiquitination}

$\alpha \mathrm{B}$-crystallin is a molecular chaperone that facilitates translocation of proteins by binding and stabilizing the target protein. ${ }^{14}$ EMT can occur through nuclear translocation of proteins, such as $\beta$-catenin, NF- $\kappa \mathrm{B}$, Notch, R-SMADs, and SMAD4, which regulate SNAIL gene expression. ${ }^{35}$ We hypothesized that the effect of $\alpha \mathrm{B}$-crystallin modulation on EMT can be mediated by a change in nuclear translocation of these proteins. Nuclear and cytosolic fractions from RPE cells were used to investigate nuclear translocation of $\beta$-catenin, $N F-\kappa B$, Notch, R-SMADs, and SMAD4. Suppression of $\alpha B$-crystallin by siRNA did not change levels of $\beta$-catenin, NF- $\kappa$ B, Notch2, or SMAD2/3 in nuclear and cytosolic fractions (Supplemental Figure S3). In contrast, the SMAD4 level was decreased in the nuclear fraction and increased in the cytosolic fraction by $\alpha \mathrm{B}$ crystallin suppression. SMAD4 was increased in the nuclear fraction and decreased in the cytosolic fraction at 24 hours after treatment by TGF- $\beta 2$ at $10 \mathrm{ng} / \mathrm{mL}$. Suppression of $\alpha \mathrm{B}$ crystallin inhibited the TGF- $\beta 2$-induced expression change of SMAD4 in the cytosolic and nuclear fractions (Figure 5A).

Next, we performed immunofluorescence staining to confirm the Western blot findings. Treatment with $\alpha \mathrm{B}$-crystallin siRNA markedly suppressed $\alpha \mathrm{B}$-crystallin expression in the cytosol. In RPE cells treated with control siRNA, SMAD4 is present in both cytosol and nucleus, and TGF- $\beta 2$ treatment $(10 \mathrm{ng} / \mathrm{mL}$ for 24 hours) induced accumulation of SMAD4 in the nucleus. 
A
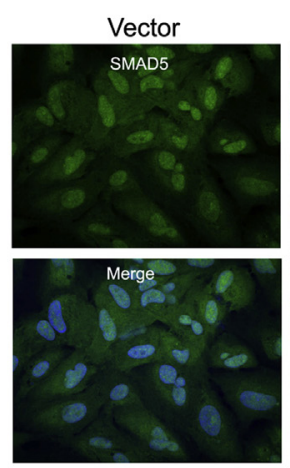

B

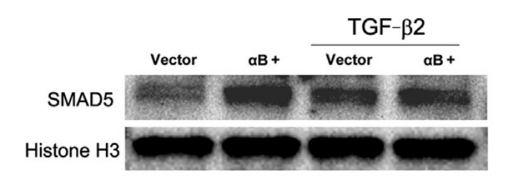

TGF- $\beta 2$
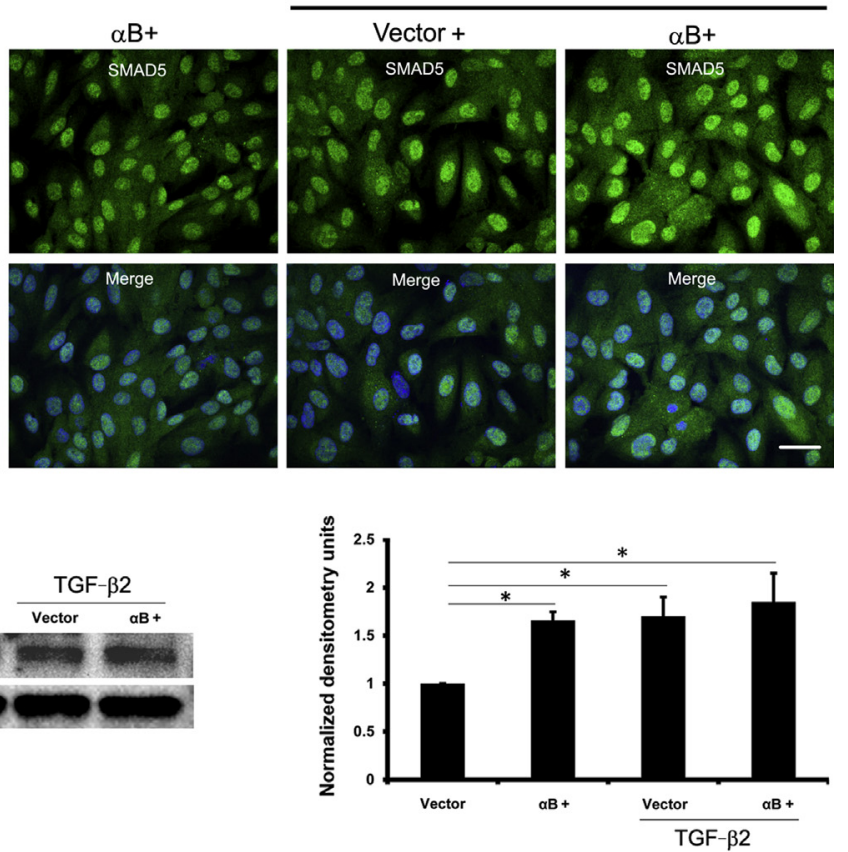

Figure $7 \quad \alpha \mathrm{B}$-crystallin $(\alpha \mathrm{B})$ induces nuclear translocation of SMAD5. Retinal pigment epithelium (RPE) cells were transfected with $\alpha \mathrm{B}$ encoding vector or empty vector, followed by treatment with $10 \mathrm{ng} / \mathrm{mL}$ transforming growth factor (TGF)- $\beta 2$ for 2 hours. A: Immunofluorescence staining showing increased nuclear translocation of SMAD5 in $\alpha \mathrm{B}$-overexpressed RPE cells versus vector-only control cells. TGF- $\beta 2$ treatment enhances nuclear translocation of SMAD5 in both vector-only and $\alpha \mathrm{B}$-overexpressed cells. B: Immunoblot analysis of SMAD5 in the nuclear extracts from the vector and $\alpha \mathrm{B}$-overexpressed cells with and without TGF- $\beta 2$ treatment; densitometric analysis of the blots from three independent experiments is shown. ${ }^{*} P<0.05$. Scale bar $=25 \mu \mathrm{m}(\mathbf{A})$.
SMAD4 expression was not seen in the nucleus after suppression of $\alpha \mathrm{B}$-crystallin by siRNA with or without TGF- $\beta 2$ treatment (Figure 5B). These findings clearly demonstrated that suppression of $\alpha \mathrm{B}$-crystallin inhibits SMAD4 nuclear translocation in RPE cells.

Monoubiquitin is a regulator of the location and activity of diverse cellular proteins. ${ }^{36}$ Recently, a regulatory role of $\alpha \mathrm{B}$-crystallin in SMAD4 monoubiquitination was reported. $^{12}$ We first isolated monotetraubiquitinated or polyubiquitinated protein from RPE cells treated with control or $\alpha B$-crystallin siRNA. Western blot analysis of ubiquitin in the whole gels shows a similar pattern of monotetraubiquitinated proteins in RPE cells transfected with $\alpha \mathrm{B}$-crystallin siRNA compared with control (Figure 5C) and showed equal loading of $\beta$-actin (Figure $5 \mathrm{C}$ ). The level of monotetraubiquitinated SMAD4 was increased in the $\alpha \mathrm{B}$-crystallin siRNA-treated cells (Figure 5D). Analysis of polyubiquitinated proteins showed they are similarly represented in $\alpha \mathrm{B}$-crystallin siRNA-treated samples and in controls (Figure 5C) with equal level of polyubiquitinated SMAD4 (Figure 5D). These results suggest that the inhibitory effect of $\alpha \mathrm{B}$-crystallin suppression on SMAD4 nuclear translocation could be mediated by monoubiquitination.

\section{Overexpression of $\alpha \mathrm{B}$-Crystallin Modulates Nuclear Translocation of SMAD4 and SMAD5}

On the basis of our finding that knockdown of $\alpha \mathrm{B}$-crystallin prevented nuclear translocation of SMAD4, we hypothesized that an increased nuclear translocation and accumulation of SMAD4 occurs in $\alpha \mathrm{B}$-crystallin-overexpressed RPE cells. To test this hypothesis, we transiently overexpressed $\alpha B$-crystallin in RPE cells. The efficacy of overexpression was verified using a green fluorescent protein-encoding plasmid and immunoblot analysis of total cell extracts probed for $\alpha \mathrm{B}$-crystallin (Figure 6A). A significant $>4.5$-fold increase in $\alpha \mathrm{B}$-crystallin protein expression was obtained in $\alpha \mathrm{B}$-crystallin-overexpressed RPE cells versus empty vector control cells (Figure 6A). Immunofluorescence studies revealed a prominent increase in nuclear accumulation of SMAD4 in $\alpha \mathrm{B}$-crystallin-overexpressed cells (Figure $6 \mathrm{~B}$ ). Immunoblot analysis for SMAD4 in nuclear fractions of the cells showed a significant $(P<0.01)$ increase in the nuclear levels of SMAD4 (Figure $6 \mathrm{C}$ ) in $\alpha \mathrm{B}$-crystallin-overexpressed cells when compared with empty vector control cells. TGF- $\beta 2$ treatment also significantly up-regulated SMAD4 accumulation in the nuclear fraction of empty vector control cells; however, no further accumulation of SMAD4 was observed in $\alpha \mathrm{B}$-crystallin-overexpressed cells (Figure 6C).

Because SMAD4 is the common mediator or co-SMAD that displays continuous shuttling between the nucleus and the cytoplasm, ${ }^{37,38}$ we determined whether its accumulation in the nucleus after $\alpha \mathrm{B}$-crystallin overexpression was associated with nuclear accumulation of receptor-regulated R-SMADs. We first evaluated SMAD2/3 because these are activated in the canonical TGF- $\beta / \mathrm{SMAD}$ signaling pathway. To determine whether $\alpha \mathrm{B}$-crystallin overexpression can alter SMAD2/3 translocation and accumulation, we extracted nuclear and cytosolic fractions from RPE cells transfected with $\alpha \mathrm{B}$-crystallin-encoding vector. Overexpression of $\alpha \mathrm{B}$-crystallin did not alter the accumulation of SMAD2/3 in the nuclei (Supplemental Figure S3). We next evaluated R-SMAD5 because recent studies showed that SMAD5 activation may occur as a noncanonical 

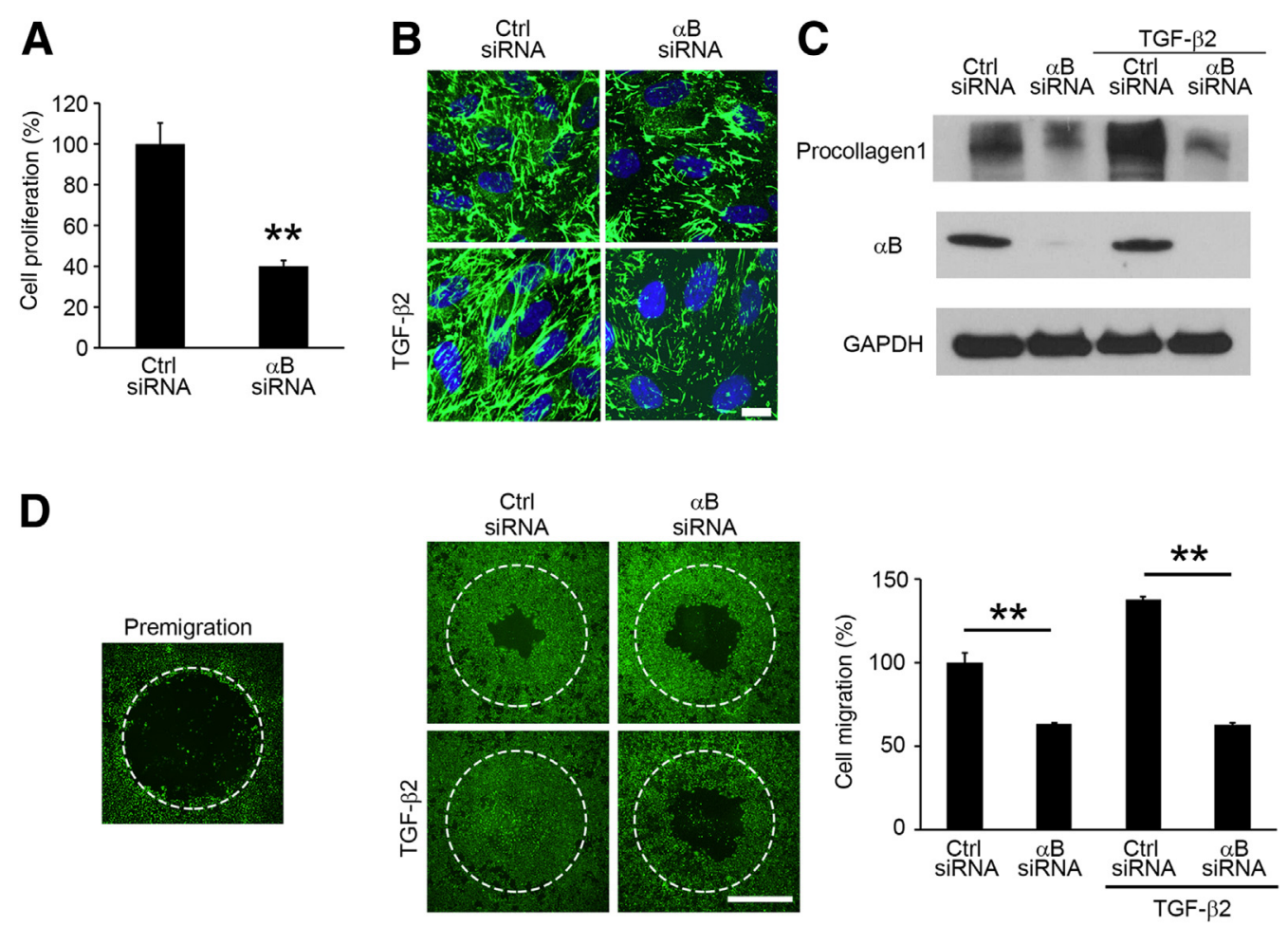

Figure 8 Inhibition of $\alpha \mathrm{B}$-crystallin $(\alpha \mathrm{B})$ expression prevents cell proliferation, migration, and fibronectin synthesis. Retinal pigment epithelium (RPE) cells were transfected with control (Ctrl) siRNA and $\alpha$ B siRNA. A: 5-Bromo-2'-deoxyuridine (BrdU) incorporations were measured to assay proliferation. B: Immunofluorescence staining of fibronectin in RPE cells with or without $10 \mathrm{ng} / \mathrm{mL}$ transforming growth factor (TGF)- $\beta 2$ stimulation for 12 hours. C: Western blot analysis of procollagen I, $\alpha \mathrm{B}$, and glyceraldehyde-3-phosphate dehydrogenase (GAPDH) in the cell lysates of RPE cells. D: For the migration assay, RPE cells were incubated after transfection for 48 hours with or without $10 \mathrm{ng} / \mathrm{mL}$ TGF- $\beta 2$. The areas of the cells (stained by calcein AM) that migrated into the detection zone (white dotted circle) were measured. Data are presented as means \pm SEM $(\mathbf{A}$ and $\mathbf{D}) . n=4$ per group $(\mathbf{A}$ and $\mathbf{D})$. ${ }^{* * P}<0.01$. Scale bars: $10 \mu \mathrm{m}($ B) $; 1 \mathrm{~mm}$ (D).

TGF- $\beta$ signaling pathway in macrophages. ${ }^{39}$ Interestingly, confocal immunofluorescence studies and immunoblot studies of nuclear fractions revealed increased SMAD5 accumulation in the nuclei of RPE after treatment with TGF- $\beta 2$ (Figure 7). Just as with SMAD4, analysis of $\alpha \mathrm{B}$ crystallin-overexpressing cells showed increased SMAD5 accumulation in the nuclei when compared with vector-only control cells (Figure 7).

\section{Suppression of aB-Crystallin Inhibits Cell Proliferation, Migration, and Fibronectin Synthesis}

EMT of RPE cells is an initial step in subretinal fibrosis that is followed by cell proliferation, migration, and ECM remodeling. ${ }^{8,40}$ Fibronectin and collagen I are the most prominent ECM components in human subretinal fibrotic lesions. ${ }^{41}$ Fibronectin provides a provisional matrix for cell migration of RPE cells. ${ }^{40,42}$ Procollagen I synthesis leads to collagen type I deposition during tissue fibrosis. ${ }^{43}$ Because $\alpha \mathrm{B}$-crystallin induced EMT, we next tested the effect of $\alpha \mathrm{B}$-crystallin inhibition on cell proliferation, migration, and fibronectin and procollagen I synthesis in RPE cells. Inhibition of $\alpha \mathrm{B}$-crystallin expression by siRNA significantly inhibited cell proliferation, as determined by decreased 5-bromo-2'-deoxyuridine incorporation at 24 hours after transfection (Figure 8A). Immunofluorescence staining showed prominently increased fibronectin expression at 12 hours after treatment with TGF- $\beta 2$. RPE cells treated by $\alpha \mathrm{B}$-crystallin siRNA showed less expression of fibronectin stimulated with or without TGF- $\beta 2$ (Figure 8B). Procollagen I expression and TGF- $\beta 2-$ induced expression of procollagen I were decreased after silencing $\alpha \mathrm{B}$-crystallin in RPE cells (Figure $8 \mathrm{C}$ ). In the cell migration assay, TGF- $\beta 2$ stimulation significantly promoted cell migration. Inhibition of $\alpha \mathrm{B}$-crystallin expression by siRNA significantly suppressed the cell migration stimulated with or without TGF- $\beta 2$ (Figure 8D).

\section{Discussion}

This study demonstrates, for the first time, the functional role of $\alpha \mathrm{B}$-crystallin in EMT of RPE and its association with subretinal fibrosis. We further show that inhibition of $\alpha \mathrm{B}$-crystallin downregulates nuclear translocation of SMAD4 in RPE cells undergoing EMT through an increase in monotetraubiquitination that can impair nuclear localization of SMAD4. We also demonstrate that overexpression of $\alpha \mathrm{B}$-crystallin results in increased nuclear accumulation of co-SMAD4 and R-SMAD5. Our studies thus identify $\alpha \mathrm{B}$-crystallin as a molecular chaperone for SMAD4, and SMAD5 as a component of a 
noncanonical TGF- $\beta 2$ signaling pathway in RPE that could bind with SMAD4, allowing their nuclear accumulation.

In the natural history of nAMD, CNV progresses to an end-stage fibrous plaque/disciform scar. ${ }^{44,45}$ Similarly, in WT mice, after laser-induced CNV reaches a maximum at day 7 after laser and starts to regress, fibrous tissue increases for up to 35 days. By contrast, in $\alpha \mathrm{B}$-crystallin knockout mice, fibrous tissue does not increase after day 21 after laser, whereas CNV regresses. In addition, the $\alpha \mathrm{B}$-crystallin expression level reaches a peak at day 21 , which can imply the facilitating role of $\alpha \mathrm{B}$-crystallin in subretinal fibrosis development. Decreased mesenchymal RPE cells in the subretinal fibrous tissue in $\alpha \mathrm{B}$-crystallin knockout mice is supported by the in vitro data showing that inhibition of $\alpha \mathrm{B}$-crystallin expression repressed EMT of RPE cells. Because EMT is an essential step of fibrotic processes, such as cell proliferation, migration, and fibronectin production, ${ }^{40}$ the effect of $\alpha \mathrm{B}$-crystallin inhibition on the process shown in vitro can cause less fibrous tissue formation in vivo.

Two recent studies demonstrated a role for $\alpha \mathrm{B}$-crystallin in the EMT process in the pathogenesis of hepatocellular carcinoma and pulmonary fibrosis. ${ }^{11,12}$ Huang et al ${ }^{11}$ showed that $\alpha \mathrm{B}$-crystallin protects $14-3-3 \zeta$ from its degradation by the proteasome leading to the activation of extracellular signal-regulated kinase signaling pathway, which can induce EMT of hepatocellular carcinoma cells. Bellaye et a ${ }^{12,46}$ found the overexpression of $\alpha \mathrm{B}$-crystallin in human and rodent fibrotic lung tissue. The authors elucidated the causal role of $\alpha \mathrm{B}$-crystallin in EMT by demonstrating that overexpression of $\alpha \mathrm{B}$-crystallin disrupted monoubiquitination of SMAD4 by interacting with transcriptional intermediary factor $1 \gamma, \mathrm{E} 3$-ubiquitin ligase and thus limiting its nuclear export. ${ }^{12,46}$ Our study in RPE showed that knockdown of $\alpha \mathrm{B}$-crystallin increased the monotetraubiquitination of SMAD4 by threefold and decreased its nuclear localization in both TGF- $\beta 2$ treated and untreated cells. Interestingly, in RPE, EMT is induced by both TGF- $\beta 2$, the major TGF- $\beta$ isoform in the RPE, and BMP4. BMP4 may be mediating its effects through regulation of $\alpha \mathrm{B}$-crystallin expression. BMP4 induction of EMT was associated with a 4.5 -fold increase in $\alpha \mathrm{B}$-crystallin, and knocking down $\alpha \mathrm{B}$-crystallin in the BMP4-treated cells reversed the induction of EMT. Previous histological findings demonstrated the expression of $\alpha \mathrm{B}$-crystallin and BMP4 in subretinal disciform scarring of human nAMD,${ }^{15,28}$ indicating that BMP4-inducible up-regulation of $\alpha \mathrm{B}$-crystallin may play a role in the pathogenesis of subretinal fibrosis.

Overexpression of $\alpha \mathrm{B}$-crystallin led to a prominent increase in SMAD4 translocation/accumulation. In canonical TGF- $\beta$ signaling, nuclear translocation of R-SMAD2/3 facilitates binding to Smad binding elements via masking the SMAD4 nuclear export signal. ${ }^{37,38}$ However, we did not find evidence that nuclear SMAD2/3 accumulation was altered after $\alpha \mathrm{B}$-crystallin knockdown or overexpression. Instead, we considered the possibility that SMAD4 stabilization in the nucleus involved other R-SMADs. Herein, we identified an alternate TGF- $\beta 2$ pathway in which treatment of RPE with TGF- $\beta 2$ increased the nuclear translocation/accumulation of SMAD5. Although SMAD5 is an integral component of the BMP signaling pathway, the noncanonical TGF- $\beta 1-$ mediated activation of SMAD5 has been demonstrated in epithelial cells ${ }^{47}$ and recently in B-cell lymphomas. ${ }^{48}$ Similarly, TGF- $\beta 1$, and not BMP, proteins activated SMAD1/5 signaling in macrophages. ${ }^{39}$ Recently, TGF- $\beta 1$ regulation of posterior lateral line formation in zebrafish was shown to be mediated by SMAD5. ${ }^{49}$ Skewing of canonical Wnt signaling by TGF- $\beta$ toward the ALK1/ SMAD1/5/8 pathway was reported to cause chondrocyte hypertrophy. ${ }^{50}$ Our new data in RPE cells reveal that $\alpha \mathrm{B}-$ crystallin overexpression increases nuclear SMAD5 accumulation. In support, overexpression of $\alpha \mathrm{A}$-crystallin, another member of the $\alpha$-crystallin family, was associated with increased SMAD3/5 expression in a pancreatic cell line. ${ }^{51}$ Thus, SMAD4 and SMAD4/SMAD5 complex play an important role in $\alpha \mathrm{B}$-crystallin-mediated EMT in RPE cells.

In the physiological condition, RPE maintains the epithelial phenotype of highly polarized cells located between the neural retina and the choroid. ${ }^{23}$ Physiological RPE cells are mitotically quiescent, with cell-cell contact inhibition mediated by the homotypic adhesion of cadherins on adjacent cells. ${ }^{52}$ In the late phase of AMD, RPE dissociation can occur because of RPE and retinal detachment subsequent to $\mathrm{CNV}$ formation. Once these contacts are disrupted and exposed by profibrotic growth factors (ie, TGF- $\beta$ and PDGF), RPE cells undergo EMT. This enables RPE to assume a mesenchymal cell phenotype, which includes enhanced migratory capacity and elevated resistance to apoptosis, as well as increased production of ECM components and proangiogenic factors, including VEGF. ${ }^{8,53,54}$ Therefore, the novel property of $\alpha \mathrm{B}$-crystallin as an EMT inducer of RPE might account for the known functional roles of $\alpha \mathrm{B}$-crystallin in $\mathrm{AMD}$, such as cytoprotection and VEGF production in response to stress stimuli. ${ }^{21,22}$

The physiological RPE monolayer with cell-cell contact showed no difference in the expression of EMT markers between WT and $\alpha \mathrm{B}$-crystallin knockout mice. RPE cells with cell-cell contact are known to preferentially express E-cadherin. ${ }^{55}$ The high expression of E-cadherin can prevent cells from undergoing EMT by limiting SNAIL gene transcription. Thus, when the epithelial phenotype is maintained with adherent junctions, the cells will not be affected by the action of stimuli triggering EMT. ${ }^{31}$ These findings might elucidate the mechanism of the absence of $\alpha \mathrm{B}$-crystallin silencing effect on EMT markers in the physiological RPE cells. Our results indicate that $\alpha \mathrm{B}$-crystallin inhibition can affect only RPE cells that have lost cadherin-mediated adhesions, but it does not influence the cellular phenotypes of the normal RPE monolayer.

Although anti-VEGF therapy for nAMD is effective as an early treatment intervention to prevent consequential fibrotic progression, its direct suppressive effect on fibrosis is yet to be proved. ${ }^{2}$ Notably, some studies reported that anti-VEGF 
therapy is associated with development of fibrosis in nAMD and proliferative diabetic retinopathy. ${ }^{56-58}$ The present study demonstrated that local $\alpha \mathrm{B}$-crystallin inhibition could suppress development of subretinal fibrosis through EMT repression. Recently, a small-molecule inhibitor that blocks the interaction between $\alpha \mathrm{B}$-crystallin and VEGF-165 was identified $^{59}$; this provides a proof of concept that perhaps an inhibitor of $\alpha \mathrm{B}$-crystallin and SMAD4 binding could be identified. Therefore, $\alpha \mathrm{B}$-crystallin would be an attractive therapeutic target for the treatment of nAMD with an advantage in controlling both $\mathrm{CNV}$ and subretinal fibrosis.

\section{Acknowledgment}

We thank Ernesto Barron for technical assistance.

\section{Supplemental Data}

Supplemental material for this article can be found at http://dx.doi.org/10.1016/j.ajpath.2015.11.014.

\section{References}

1. Ambati J, Fowler BJ: Mechanisms of age-related macular degeneration. Neuron 2012, 75:26-39

2. Daniel E, Toth CA, Grunwald JE, Jaffe GJ, Martin DF, Fine SL, Huang J, Ying GS, Hagstrom SA, Winter K, Maguire MG: Risk of scar in the comparison of age-related macular degeneration treatments trials. Ophthalmology 2014, 121:656-666

3. Kudelka M, Grossniklaus H, Mandell K: Emergence of dual VEGF and PDGF antagonists in the treatment of exudative agerelated macular degeneration. Expert Rev Ophthalmol 2013, 8 . 475-484

4. Ambati J, Atkinson JP, Gelfand BD: Immunology of age-related macular degeneration. Nat Rev Immunol 2013, 13:438-451

5. Wree A, McGeough MD, Pena CA, Schlattjan M, Li H, Inzaugarat ME, Messer K, Canbay A, Hoffman HM, Feldstein AE: NLRP3 inflammasome activation is required for fibrosis development in NAFLD. J Mol Med (Berl) 2014, 92:1069-1082

6. Lavalette S, Raoul W, Houssier M, Camelo S, Levy O, Calippe B, Jonet L, Behar-Cohen F, Shemtob S, Guillonneau X, Combadiere C, Sennlaub F: Interleukin-1b inhibition prevents choroidal neovascularization and does not exacerbate photoreceptor degeneration. Am J Pathol 2011, 178:2416-2423

7. Espinosa-Heidmann DG, Reinoso MA, Pina Y, Csaky KG, Caicedo A, Cousins SW: Quantitative enumeration of vascular smooth muscle cells and endothelial cells derived from bone marrow precursors in experimental choroidal neovascularization. Exp Eye Res 2005, 80:369-378

8. Ishikawa K, Kannan R, Hinton DR: Molecular mechanisms of subretinal fibrosis in age-related macular degeneration. Exp Eye Res 2016, 142:19-25

9. Basha E, O'Neill H, Vierling E: Small heat shock proteins and alphacrystallins: dynamic proteins with flexible functions. Trends Biochem Sci 2012, 37:106-117

10. Wettstein G, Bellaye PS, Micheau O, Bonniaud P: Small heat shock proteins and the cytoskeleton: an essential interplay for cell integrity? Int J Biochem Cell Biol 2012, 44:1680-1686

11. Huang XY, Ke AW, Shi GM, Zhang X, Zhang C, Shi YH, Wang XY, Ding ZB, Xiao YS, Yan J, Qiu SJ, Fan J, Zhou J: alphaB-crystallin complexes with 14-3-3zeta to induce epithelial-mesenchymal transition and resistance to sorafenib in hepatocellular carcinoma. Hepatology 2013, 57:2235-2247

12. Bellaye PS, Wettstein G, Burgy O, Besnard V, Joannes A, Colas J, Causse S, Marchal-Somme J, Fabre A, Crestani B, Kolb M, Gauldie J, Camus P, Garrido C, Bonniaud P: The small heat-shock protein alphaB-crystallin is essential for the nuclear localization of Smad4: impact on pulmonary fibrosis. J Pathol 2014, 232:458-472

13. Johnson PT, Brown MN, Pulliam BC, Anderson DH, Johnson LV: Synaptic pathology, altered gene expression, and degeneration in photoreceptors impacted by drusen. Invest Ophthalmol Vis Sci 2005, $46: 4788-4795$

14. Kannan R, Sreekumar PG, Hinton DR: Novel roles for alphacrystallins in retinal function and disease. Prog Retin Eye Res 2012, 31:576-604

15. De S, Rabin DM, Salero E, Lederman PL, Temple S, Stern JH: Human retinal pigment epithelium cell changes and expression of alphaB-crystallin: a biomarker for retinal pigment epithelium cell change in age-related macular degeneration. Arch Ophthalmol 2007, 125:641-645

16. Nakata K, Crabb JW, Hollyfield JG: Crystallin distribution in Bruch's membrane-choroid complex from AMD and age-matched donor eyes. Exp Eye Res 2005, 80:821-826

17. Zhou P, Kannan R, Spee C, Sreekumar PG, Dou G, Hinton DR: Protection of retina by alphaB crystallin in sodium iodate induced retinal degeneration. PLoS One 2014, 9:e98275

18. Dou G, Sreekumar PG, Spee C, He S, Ryan SJ, Kannan R, Hinton DR: Deficiency of alphaB crystallin augments ER stressinduced apoptosis by enhancing mitochondrial dysfunction. Free Radic Biol Med 2012, 53:1111-1122

19. Yaung J, Kannan R, Wawrousek EF, Spee C, Sreekumar PG, Hinton DR: Exacerbation of retinal degeneration in the absence of alpha crystallins in an in vivo model of chemically induced hypoxia. Exp Eye Res 2008, 86:355-365

20. Yaung J, Jin M, Barron E, Spee C, Wawrousek EF, Kannan R, Hinton DR: alpha-Crystallin distribution in retinal pigment epithelium and effect of gene knockouts on sensitivity to oxidative stress. Mol Vis 2007, 13:566-577

21. Sreekumar PG, Spee C, Ryan SJ, Cole SP, Kannan R, Hinton DR: Mechanism of RPE cell death in alpha-crystallin deficient mice: a novel and critical role for MRP1-mediated GSH efflux. PLoS One 2012, 7:e33420

22. Kase S, He S, Sonoda S, Kitamura M, Spee C, Wawrousek E, Ryan SJ, Kannan R, Hinton DR: alphaB-crystallin regulation of angiogenesis by modulation of VEGF. Blood 2010, 115: $3398-3406$

23. Sonoda S, Spee C, Barron E, Ryan SJ, Kannan R, Hinton DR: A protocol for the culture and differentiation of highly polarized human retinal pigment epithelial cells. Nat Protoc 2009, 4: $662-673$

24. Brady JP, Garland DL, Green DE, Tamm ER, Giblin FJ, Wawrousek EF: AlphaB-crystallin in lens development and muscle integrity: a gene knockout approach. Invest Ophthalmol Vis Sci 2001, 42:2924-2934

25. Zhu Y, Lu Q, Shen J, Zhang L, Gao Y, Shen X, Xie B: Improvement and optimization of standards for a preclinical animal test model of laser induced choroidal neovascularization. PLoS One 2014, 9: e94743

26. Sreekumar PG, Zhou J, Sohn J, Spee C, Ryan SJ, Maurer BJ, Kannan R, Hinton DR: N-(4-hydroxyphenyl) retinamide augments laser-induced choroidal neovascularization in mice. Invest Ophthalmol Vis Sci 2008, 49:1210-1220

27. Ishikawa $\mathrm{K}$, Yoshida $\mathrm{S}$, Nakao S, Nakama T, Kita $\mathrm{T}$, Asato $\mathrm{R}$, Sassa Y, Arita R, Miyazaki M, Enaida H, Oshima Y, Murakami N, Niiro H, Ono J, Matsuda A, Goto Y, Akashi K, Izuhara K, Kudo A, Kono T, Hafezi-Moghadam A, Ishibashi T: Periostin promotes the generation of fibrous membranes in proliferative vitreoretinopathy. FASEB J 2014, 28:131-142 
28. Zhu D, Deng X, Xu J, Hinton DR: What determines the switch between atrophic and neovascular forms of age related macular degeneration? the role of BMP4 induced senescence. Aging (Albany NY) 2009, 1:740-745

29. Ciumas M, Eyries M, Poirier O, Maugenre S, Dierick F, Gambaryan N, Montagne K, Nadaud S, Soubrier F: Bone morphogenetic proteins protect pulmonary microvascular endothelial cells from apoptosis by upregulating alpha-B-crystallin. Arterioscler Thromb Vasc Biol 2013, 33:2577-2584

30. Xu J, Zhu D, He S, Spee C, Ryan SJ, Hinton DR: Transcriptional regulation of bone morphogenetic protein 4 by tumor necrosis factor and its relationship with age-related macular degeneration. FASEB J 2011, 25:2221-2233

31. de Herreros AG, Peiro S, Nassour M, Savagner P: Snail family regulation and epithelial mesenchymal transitions in breast cancer progression. J Mammary Gland Biol Neoplasia 2010, 15:135-147

32. Li H, Li M, Xu D, Zhao C, Liu G, Wang F: Overexpression of Snail in retinal pigment epithelial triggered epithelial-mesenchymal transition. Biochem Biophys Res Commun 2014, 446:347-351

33. Hirasawa M, Noda K, Noda S, Suzuki M, Ozawa Y, Shinoda K, Inoue M, Ogawa $\mathrm{Y}$, Tsubota K, Ishida S: Transcriptional factors associated with epithelial-mesenchymal transition in choroidal neovascularization. Mol Vis 2011, 17:1222-1230

34. Pfeffer BA, Flanders KC, Guerin CJ, Danielpour D, Anderson DH: Transforming growth factor beta 2 is the predominant isoform in the neural retina, retinal pigment epithelium-choroid and vitreous of the monkey eye. Exp Eye Res 1994, 59:323-333

35. Azmi AS: Unveiling the role of nuclear transport in epithelial-tomesenchymal transition. Curr Cancer Drug Targets 2013, 13: 906-914

36. Hicke L: Protein regulation by monoubiquitin. Nat Rev Mol Cell Biol 2001, 2:195-201

37. Pierreux CE, Nicolás FJ, Hill CS: Transforming growth factor betaindependent shuttling of Smad4 between the cytoplasm and nucleus. Mol Cell Biol 2000, 20:9041-9054

38. Xiao Z, Latek R, Lodish HF: An extended bipartite nuclear localization signal in Smad4 is required for its nuclear import and transcriptional activity. Oncogene 2003, 22:1057-1069

39. Nurgazieva D, Mickley A, Moganti K, Ming W, Ovsyi I, Popova A, Sachindra, Awad K, Wang N, Bieback K, Goerdt S, Kzhyshkowska J, Gratchev A: TGF- $\beta 1$, but not bone morphogenetic proteins, activates Smad1/5 pathway in primary human macrophages and induces expression of proatherogenic genes. J Immunol 2015, 194:709-718

40. Kent D, Sheridan C: Choroidal neovascularization: a wound healing perspective. Mol Vis 2003, 9:747-755

41. Das A, Puklin JE, Frank RN, Zhang NL: Ultrastructural immunocytochemistry of subretinal neovascular membranes in age-related macular degeneration. Ophthalmology 1992, 99:1368-1376

42. Jin M, He S, Worpel V, Ryan SJ, Hinton DR: Promotion of adhesion and migration of RPE cells to provisional extracellular matrices by TNF-alpha. Invest Ophthalmol Vis Sci 2000, 41:4324-4332

43. Cutroneo KR: How is type I procollagen synthesis regulated at the gene level during tissue fibrosis. J Cell Biochem 2003, 90:1-5

44. Lim LS, Mitchell P, Seddon JM, Holz FG, Wong TY: Age-related macular degeneration. Lancet 2012, 379:1728-1738
45. Ryan SJ: The development of an experimental model of subretinal neovascularization in disciform macular degeneration. Trans Am Ophthalmol Soc 1979, 77:707-745

46. Bellaye PS, Burgy O, Colas J, Fabre A, Marchal-Somme J, Crestani B, Kolb M, Camus P, Garrido C, Bonniaud P: Antifibrotic role of alphaB-crystallin inhibition in pleural and subpleural fibrosis. Am J Respir Cell Mol Biol 2015, 52:244-252

47. Daly AC, Randall RA, Hill CS: Transforming growth factor betainduced Smad1/5 phosphorylation in epithelial cells is mediated by novel receptor complexes and is essential for anchorage-independent growth. Mol Cell Biol 2008, 28:6889-6902

48. Jiang D, Aguiar RC: MicroRNA-155 controls RB phosphorylation in normal and malignant B lymphocytes via the noncanonical TGFB1/SMAD5 signaling module. Blood 2014, 123:86-93

49. Xing C, Gong B, Xue Y, Han Y, Wang Y, Meng A, Jia S: TGFß1a regulates zebrafish posterior lateral line formation via Smad5 mediated pathway. J Mol Cell Biol 2015, 7:48-61

50. van den Bosch $\mathrm{MH}$, Blom $\mathrm{AB}$, van Lent PL, van Beuningen HM, Blaney Davidson EN, van der Kraan PM, van den Berg WB: Canonical Wnt signaling skews TGF- $\beta$ signaling in chondrocytes towards signaling via ALK1 and Smad 1/5/8. Cell Signal 2014, 26:951-958

51. Deng M, Chen PC, Xie S, Zhao J, Gong L, Liu J, Zhang L, Sun S, Liu J, Ma H, Batra SK, Li DW: The small heat shock protein alphaA-crystallin is expressed in pancreas and acts as a negative regulator of carcinogenesis. Biochim Biophys Acta 2010, 1802: 621-631

52. Binder S, Stanzel BV, Krebs I, Glittenberg C: Transplantation of the RPE in AMD. Prog Retin Eye Res 2007, 26:516-554

53. Tiwari N, Gheldof A, Tatari M, Christofori G: EMT as the ultimate survival mechanism of cancer cells. Semin Cancer Biol 2012, 22:194-207

54. Schlingemann RO: Role of growth factors and the wound healing response in age-related macular degeneration. Graefes Arch Clin Exp Ophthalmol 2004, 242:91-101

55. Burke JM, Cao F, Irving PE, Skumatz CM: Expression of E-cadherin by human retinal pigment epithelium: delayed expression in vitro. Invest Ophthalmol Vis Sci 1999, 40:2963-2970

56. Barikian A, Mahfoud Z, Abdulaal M, Safar A, Bashshur ZF: Induction with intravitreal bevacizumab every two weeks in the management of neovascular age-related macular degeneration. Am J Ophthalmol 2015, 159:131-137

57. Van Geest RJ, Lesnik-Oberstein SY, Tan HS, Mura M, Goldschmeding R, Van Noorden CJ, Klaassen I, Schlingemann RO: A shift in the balance of vascular endothelial growth factor and connective tissue growth factor by bevacizumab causes the angiofibrotic switch in proliferative diabetic retinopathy. $\mathrm{Br} \mathrm{J}$ Ophthalmol 2012, 96:587-590

58. Arevalo JF, Maia M, Flynn HW Jr, Saravia M, Avery RL, Wu L, Eid Farah M, Pieramici DJ, Berrocal MH, Sanchez JG: Tractional retinal detachment following intravitreal bevacizumab (Avastin) in patients with severe proliferative diabetic retinopathy. Br J Ophthalmol 2008, 92:213-216

59. Chen Z, Ruan Q, Han S, Xi L, Jiang W, Jiang H, Ostrov DA, Cai J: Discovery of structure-based small molecule inhibitor of $\alpha \mathrm{B}$-crystallin against basal-like/triple-negative breast cancer development in vitro and in vivo. Breast Cancer Res Treat 2014, $145: 45-59$ 